\title{
Linkages between the South and East Asian Monsoon Water Vapor Transport during Boreal Summer $\mathscr{A}$
}

\author{
YONG LIU \\ Center for Monsoon System Research, Institute of Atmospheric Physics, Chinese Academy of Sciences, and \\ Joint Center for Global Change Studies, Beijing, China \\ RONGHUI HUANG \\ Center for Monsoon System Research, Institute of Atmospheric Physics, Chinese Academy of Sciences, and \\ Institute of Earth Sciences, University of Chinese Academy of Sciences, and State Key Laboratory of Numerical \\ Modeling for Atmospheric Sciences and Geophysical Fluid Dynamics, Institute of Atmospheric Physics, \\ Chinese Academy of Sciences, Beijing, China
}

(Manuscript received 3 August 2018, in final form 29 March 2019)

\begin{abstract}
This study provides a water vapor transport (WVT) perspective on the linkages between the South Asian and East Asian summer monsoons (SASM and EASM) and indicates two robustly coupled modes of the vertical integrated WVT (VIWVT) over the two monsoons that accounts for above $90 \%$ of the total squared covariance fraction. The first coupled mode [singular value decomposition mode 1 (SVD1 mode)] depicts a meridional linkage between the meridional dipole VIWVT anomalies over both the SASM and EASM, while the second coupled mode (SVD2 mode) illustrates a zonal connection of an anomalous cyclonic/anticyclonic VIWVT over the SASM and a zonal wavelike VIWVT over the EASM. The SVD1 mode is linked through the anomalous subtropical high over the western North Pacific (WNPSH) and is primarily associated with the transition phase of El Niño/La Niña (ENSO) and simultaneous Indian Ocean basin mode (IOBM) SST warming/cooling. The meridional connection of the VIWVT in the SVD1 mode experienced a clear intensification since the late 1970s that may be attributed to the strengthened impacts of the ENSO/IOBM on the EASM and SASM after the late 1970s. The SVD2 mode is connected by the circumglobal teleconnection (CGT) pattern and related to the developing phase of ENSO and summer North Atlantic tripole (NAT) SST anomalies. The zonal VIWVT connection in SVD2 mode is strongly modulated by the SASM-CGT connections and reveals significant weakening since the late 1970s but reintensifies after the early 1990s. This may be associated with the weakened ENSO-SASM relationship after the late 1970s and interdecadal decreasing of the all Indian summer rainfall since the early 1990s.
\end{abstract}

\section{Introduction}

The South Asian and East Asian summer monsoons (hereafter referred to as the SASM and EASM, respectively) are two major components of the Asian summer monsoon (ASM) and have large social and economic impacts over Asia. The two monsoons are interactive and connected with each other, and plenty of studies have investigated the linkages between the two

\footnotetext{
Supplemental information related to this paper is available at the Journals Online website: https://doi.org/10.1175/JCLI-D-180498.s1.
}

Corresponding author: Yong Liu, liuyong@mail.iap.ac.cn monsoons (Day et al. 2015; Ding and Liu 2008; Hu et al. 2005; Kripalani and Kulkarni 1997, 2001; Wang and Huang 2006; Wu and Wang 2002). Among these studies, many cases focused on the relationship between the regional-mean summer rainfall variations over the two monsoons, in particular the in-phase relationship of the summer rainfall variations over all India with that over northern China (Kripalani and Kulkarni 2001; Wu 2002, 2017) and the out-of-phase relationship with that over South Korea and Japan (Choi et al. 2014; Kim et al. 2002; Yun et al. 2014). The changes in their connections

Publisher's Note: This article was revised on 1 July 2019 to correct the first author's name, which was mistakenly reversed when originally published. 
have also been investigated extensively (Ha et al. 2017; Wu 2017; and many others). Recently, Huang et al. (2017) documented the connections of the leading modes of the summer rainfall over the two monsoons and indicated that the in-phase (out-of-phase) relationship of the Indian summer rainfall with northern China (South Korea and Japan) summer rainfall may be included in the connections of the above leading modes. Therefore, we should be careful to interpret the connections of the summer rainfall over the two monsoons.

The connections of the summer rainfall variations over the two monsoons are linked through two pathways (Wu 2017). One is through the anomalous atmospheric circulation over the lower latitudes that involves the western North Pacific subtropical high (WNPSH) (Chowdary et al. 2014a; Kosaka et al. 2013; Wang et al. 2001; Zhang et al. 2017) and the East Asia-Pacific/ Pacific-Japan teleconnection pattern (EAP/PJ) (Huang and Li 1987; Nitta 1987), and the other one is via an extratropical Silk Road/circumglobal teleconnection (CGT) pattern along the upper-level westerly jet stream (Ding and Wang 2005; Enomoto et al. 2003; Huang et al. 2011; Huang et al. 2013; Kosaka et al. 2009; Lu et al. 2002; Wu 2002). These anomalous circulations are attributed to the impacts of the external forcings (Hu et al. 2005; Kripalani and Singh 1993; Kripalani and Kulkarni 1997; Kripalani et al. 1997; Lau and Wu 2001; Lau et al. 2000; Wu 2017), such as ENSO, the Indian Ocean dipole/ basin mode (IODM/IOBM), and Eurasian snow extent. Two comprehensive reviews on this topic have been recently provided by Wu (2017) and Ha et al. (2017).

In addition to the linkages of the SASM-EASM summer rainfall variations, the connections of water vapor transport (WVT) over the two monsoons have also been noticed. Based on the vertically integrated zonal WVT (VIWVT) averaged over the region $0^{\circ}-$ $20^{\circ} \mathrm{N}, 80^{\circ}-100^{\circ} \mathrm{E}$, Zhang (2001) indicated that strong (weak) VIWVT from the SASM region is accompanied by less (more) VIWVT over the EASM, which results in less (more) rainfall over the middle and lower reaches of the Yangtze River valley. Meanwhile, the VIWVT over northern China shows positive correlation with that from the SASM region (Zhang et al. 1999), and stronger (weaker) northward WVT over East Asia that favors more (less) rainfall over northern China corresponds to more (less) Indian summer rainfall (Liu and Ding 2008). These features are responsible for the in-phase relationship between the Indian and northern China summer rainfall variations and imply the essential role of the WVT in connecting the SASM and EASM. In this respect, studying the linkages of the WVT over the SASM and EASM is an effective way to uncover the SASMEASM connections.
As one of the important components in the ASM, the VIWVT shows significant influence on the monsoon rainfall and plays a vital role in the interannual and interdecadal variability of the summer rainfall over the two monsoon regions (Huang et al. 2003; Li and Zhou 2012; Li et al. 2012; Zhou and Yu 2005). Revealing the linkages of the VIWVT over the two monsoons may provide some useful reference to understand the SASM-EASM linkages. Therefore, with the goal to provide a WVT perspective on the linkages of the two monsoons, the present study 1) investigates the characteristics of the coupled modes of the SASM and EASM VIWVT based on four reanalysis datasets and their association with the summer rainfall variations over the ASM, 2) explores the key factors and processes for the coupled modes (particular attention is paid to their association with the tropical Indo-Pacific Ocean SST, boreal summer teleconnection patterns, and the WNPSH), and 3) analyzes the interdecadal changes in their linkages and underlying mechanisms.

The remainder of this paper is organized as follows. Section 2 describes the datasets and methodology. Section 3 illustrates the features of the coupled modes of the VIWVT over the two monsoons, their association with ASM rainfall and key pathways for their linkages. Section 4 presents the role of ENSO cycle on the connections of the SASM and EASM VIWVT. The interdecadal changes in the linkages over the two monsoons are discussed in section 5. At last, the key findings along with discussions are given in section 6 .

\section{Data and methods}

The datasets used include 1) monthly global SST from the Hadley Centre (Rayner et al. 2003); 2) the monthly precipitation datasets from NOAA's precipitation reconstruction (PREC) dataset (Chen et al. 2002); and 3) four monthly long-term reanalysis datasets from the National Centers for Environmental Prediction (NCEP)National Center for Atmospheric Research (NCAR) reanalysis dataset (Kalnay et al. 1996), the Japanese 55-year Reanalysis (JRA-55) dataset (Kobayashi et al. 2015), the ECMWF Twentieth Century Reanalysis (ERA-20C) dataset (1948-2010; Poli et al. 2016), and the combined ECMWF ERA-40 (1948-78; Uppala et al. 2005) and ERA-Interim datasets (1979-2015; Dee et al. 2011) by removing the climatological mean difference between the two datasets following the method of Wang et al. (2012). The four reanalysis datasets are interpolated onto the same $2.5^{\circ} \times 2.5^{\circ}$ grid points, and are referred to herein as NCEP1, JRA55, ERA20C, and ERA40I, respectively. The time period concerned in this study is from 1961 to 2014 (from 1961 to 2010 for ERA20C) and the seasonal mean is 
refered to as the definition in Northern Hemisphere, such as summer mean is the average of June, July and August (JJA). The linear trend of all seasonal mean variables is subtracted to remove long-term scale variations.

The VIWVT flux $(\mathbf{Q})$ in the troposphere from the surface to $300 \mathrm{hPa}$ is calculated as

$$
\mathbf{Q}=\frac{1}{g} \int_{300}^{p_{s}} q \mathbf{V} d p,
$$

where $g, q, \mathbf{V}$, and $p_{s}$ are the acceleration of gravity, specific humidity, horizontal wind vector, and surface pressure, respectively. The divergence of the VIWVT flux $(\mathbf{Q})$ contributes largely in the local water cycle balance and is approximatively expressed as formula (2), which can be further divided into the dynamical and thermal components contributed respectively by the divergence of the horizontal wind and moisture advection with the residual term neglected (Seager et al. 2010):

$$
\begin{aligned}
\nabla \cdot \mathbf{Q} & \approx \frac{1}{g} \int_{300}^{p_{s}} \nabla \cdot(q \mathbf{V}) d p \\
& \approx \frac{1}{g} \int_{300}^{p_{s}} q \nabla \cdot(\mathbf{V}) d p+\frac{1}{g} \int_{300}^{p_{s}} \mathbf{V} \cdot \nabla q d p .
\end{aligned}
$$

To delineate the connections of the SASM and EASM VIWVT, we apply the singular value decomposition (SVD) analysis on the summer $\mathbf{Q}$ vectors (zonal and meridional direction) over the SASM $\left(5^{\circ}-30^{\circ} \mathrm{N}, 60^{\circ}-100^{\circ} \mathrm{E}\right)$ and EASM $\left(10^{\circ}-50^{\circ} \mathrm{N}, 100^{\circ}-150^{\circ} \mathrm{E}\right)$, and employ the first two coupled modes in the present study. Here, the domains for the SASM and EASM are slightly different from Ding (2007); in particular, the EASM domain comprises part of WNP summer monsoon region, which aims to obtain the integrity of the VIWVT system (such as the subtropical anticyclone or anticyclonic VIWVT) over the East Asia-WNP region. The coupled modes are much more robust even though we shrink the domains slightly for the SASM and EASM.

To investigate the relationship of the coupled modes with large-scale climate anomalies, several climate indices are used in the following study. The Niño-3.4 index is defined as the SST anomalies (SSTAs) averaged over the region $5^{\circ} \mathrm{S}$ $5^{\circ} \mathrm{N}, 170^{\circ}-120^{\circ} \mathrm{W}$ to represent ENSO. The IOBM index is the SSTAs averaged over the region $20^{\circ} \mathrm{S}-20^{\circ} \mathrm{N}, 40^{\circ}-100^{\circ} \mathrm{E}$. The CGT index is defined as the $200-\mathrm{hPa}$ geopotential height averaged over the area $35^{\circ}-40^{\circ} \mathrm{N}, 60^{\circ}-70^{\circ} \mathrm{E}$ (Ding and Wang 2005). In addition, a WNPSH index is defined as the $850-\mathrm{hPa}$ geopotential height (GPH) averaged over the western Pacific $\left(10^{\circ}-30^{\circ} \mathrm{N}, 110^{\circ}-150^{\circ} \mathrm{E}\right)$ (Song and Zhou 2015).

Common statistical analysis methods are also used, such as the correlation and regression analysis and the two-tailed Student's $t$ test methods. In the running correlation analysis, we estimate the effective degree of freedom $N_{\text {eff }}$ in each running correlation period (Metz 1991). The $N_{\text {eff }}$ for the correlations of time series $X$ and $Y$ are evaluated as

$$
N_{\text {eff }}=N / \max \left[1,1+2 \sum_{\tau=1}^{\tau_{\max }}(1-\tau / N) r_{X}(\tau) r_{Y}(\tau)\right] .
$$

Here, $N$ denotes the data length, and $r_{X}(\tau) / r_{Y}(\tau)$ is an autocorrelation of time series $X / Y$ with a lag of $\tau$ years. For simplicity, the maximum lag $\tau_{\max }$ is set as the maximum number less than $N / 2$.

\section{The linkages betwen the SASM and EASM VIWVT}

\section{a. Spatial and temporal features of the coupled modes}

For the sake of simplicity, the first two coupled modes of the VIWVT over SASM and EASM are referred as SVD1_SASM, SVD2_SASM, SVD1_EASM, and SVD2 EASM, respectively, which are shown in Figs. 1 and 2 (based on NCEP1) and Figs. S1 and S2 in the online supplemental material (based on the other three datasets). Before any analysis, we first check the consistency of the two SVD modes (SVD1 and SVD2) among the four datasets by calculating the correlations of the time series corresponding to the specific SVD mode (Figs. 1c,d and $2 \mathrm{c}, \mathrm{d}$ ), respectively. As listed in Table 1, the first two SVD modes of the VIWVT over the SASM/EASM reveal high consistency among the four datasets that have extremely high correlation coefficients exceeding 0.9 (0.83) during the period 1961-2015 (1961-2010). In addition, the largescale atmospheric circulations, rainfall, and SST anomalies related to the two SVD modes are also identical to each other among the four datasets. For convenience, the following analyses related to the two SVD modes are mainly based on the NCEP1 dataset. Those based on the other three datasets are provided in the supplemental material for reference.

Figure 1 displays the anomalous VIWVT related to SVD1_SASM and SVD1_EASM, whose spatial characteristics are almost identical to each other among the four datasets (Fig. 1; see also Fig. S1). The homogeneous mode of the SVD1_SASM is characterized by an anomalous dipole VIWVT pattern with an anomalous cyclone and anticyclone over the southern and northeastern SASM (Fig. 1a). It is accompanied by a meridional dipole VIWVT pattern over the EASM that has an anomalous anticyclone over the subtropical EASM and an anomalous cyclone over the midlatitude of EASM except that the cyclonic VIWVT in the midlatitudes is much weaker than its counterpart in the subtropics 
(a) SVD1 SASM

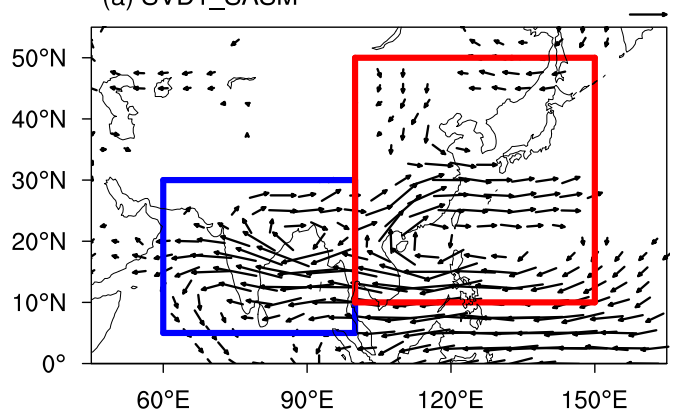

(c) PC1_SASM $(75 \% / 75.9 \% / 74.8 \% / 85.3 \%)$

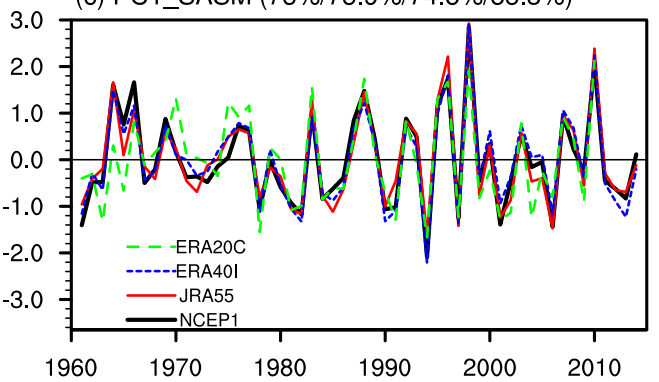

(b) SVD1 EASM

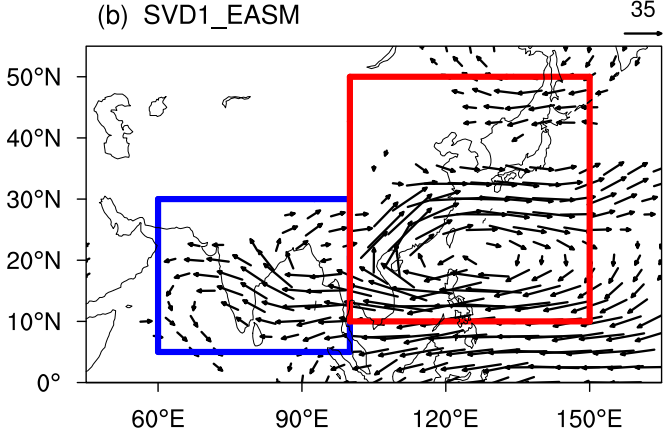

(d) PC1_EASM (75\%/75.9\%/74.8\%/85.3\%)

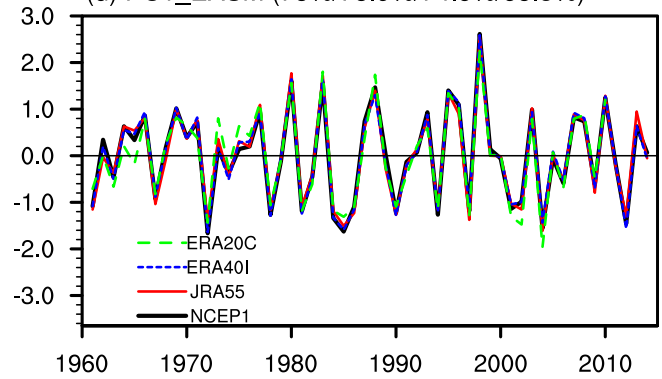

FIG. 1. (a),(b) Regressed anomalies of the VIWVT against the time series of the (left) SVD1_SASM and (right) SVD1_EASM based on the NCEP1 dataset (units: $\mathrm{kg} \mathrm{m}^{-2} \mathrm{~s}^{-1}$ ). (c),(d) The time series of the SVD1_SASM and SVD1_EASM for JRA55, ERA40I, ERA20C, and NCEP1. Vectors with anomalies significant beyond the 95\% confidence level are plotted. The blue (red) box is the SASM (EASM) domain.

(Fig. 1b). The heterogeneous mode of the VIWVT over the two monsoons bears a great similarity in the VIWVT anomalies to those in the homogeneous mode (Figs. 1a,b). In relation to the whole ASM region, the anomalous

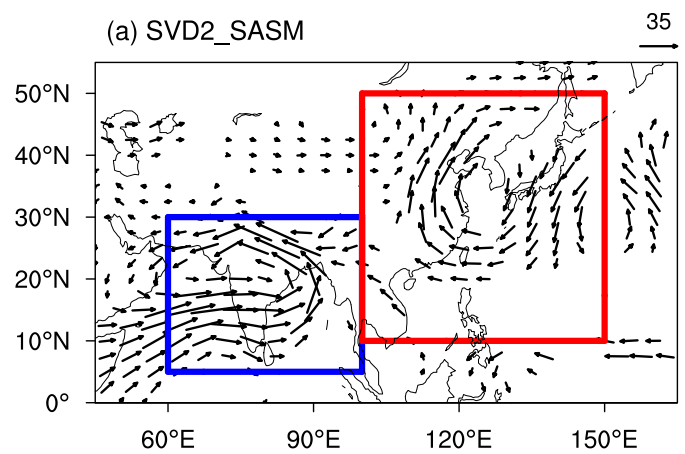

(c) PC2_SASM $(13.8 \% / 13.4 \% / 15 \% / 7.8 \%)$

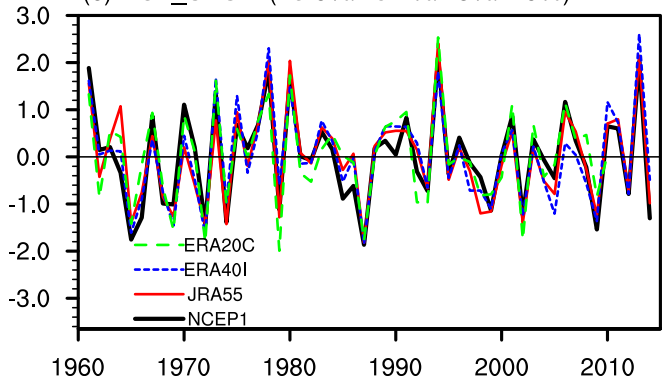

dipole VIWVT over the SASM merges with the anticyclonic VIWVT over the southern EASM along $100^{\circ} \mathrm{E}$, which together exhibit a meridional tripole structure with cyclonic VIWVT in the tropics and midlatitudes and

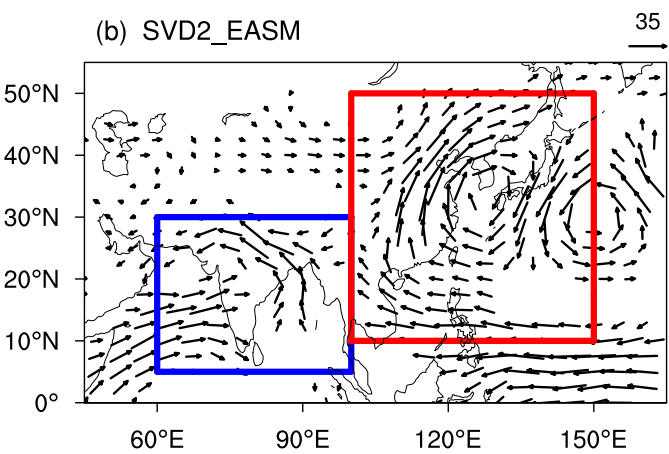

(d) PC2_EASM $(13.8 \% / 13.4 \% / 15 \% / 7.8 \%)$

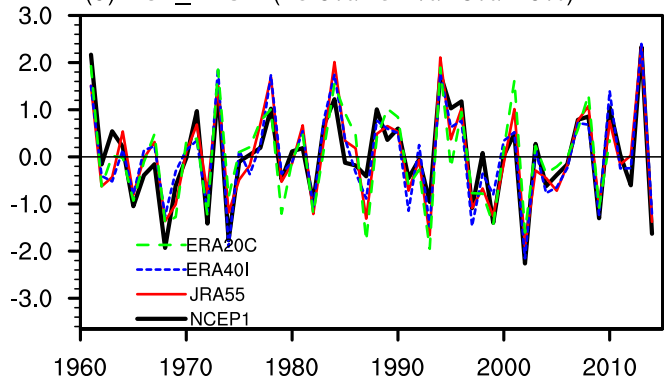

FIG. 2. As in Fig. 1, but for (left) SVD2_SASM and (right) SVD2_EASM. 
TABLE 1. Correlation coefficients of the time series of the SVD1 (SASM/EASM) and SVD2 (SASM/EASM) among different datasets for the periods 1961-2014. All of the correlation coefficients exceed the $99.9 \%$ confidence level based on the two-tailed Student's $t$ test.

\begin{tabular}{|c|c|c|c|c|c|c|}
\hline \multirow[b]{2}{*}{ SASM/EASM } & \multicolumn{3}{|c|}{ SVD1 (SASM/EASM) } & \multicolumn{3}{|c|}{ SVD2 (SASM/EASM) } \\
\hline & NCEP1 & ERA40I & JRA55 & NCEP1 & ERA40I & JRA55 \\
\hline NCEP1 & $1 / 1$ & - & - & $1 / 1$ & - & - \\
\hline ERA40I & $0.975 / 0.997$ & $1 / 1$ & - & $0.919 / 0.926$ & $1 / 1$ & - \\
\hline JRA55 & $0.959 / 0.99$ & $0.96 / 0.99$ & $1 / 1$ & $0.92 / 0.903$ & $0.94 / 0.95$ & $1 / 1$ \\
\hline ERA20C (1961-2010) & $0.84 / 0.97$ & $0.85 / 0.97$ & $0.87 / 0.97$ & $0.89 / 0.84$ & $0.83 / 0.86$ & $0.9 / 0.94$ \\
\hline
\end{tabular}

anticyclonic WVT in the subtropics although there are two centers of the anomalous VIWVT in subtropical Asia. These features resemble the composited VIWVT anomalies during weak Indian monsoon VIWVT years [Fig. 3b in Zhang (2001)] and the regressed VIWVT anomalies corresponding to the first EOF mode of summer rainfall in China [Fig. 4a in Zhou and $\mathrm{Yu}$ (2005)]. The SVD1 mode accounts for about $75 \%$, $75.9 \%, 74.8 \%$, and $85.3 \%$ (NCEP1, JRA55, ERA40I, and ERA20C) of the total squared covariance fraction and the associated time series of the VIWVT over the SASM (Fig. 1c) and EASM (Fig. 1d) yield a correlation coefficient of beyond 0.76 for the four datasets (Table 2), suggesting the dominant contribution of the SVD1 mode in the coupling of the VIWVT over the SASM and EASM. In fact, this mode depicts a meridional connection of the VIWVT over the two monsoons and represents a closely out-of-phase relationship between the VIWVT over the central-eastern SASM and central or subtropical EASM (along the mei-yu belt), namely that stronger VIWVT over central-eastern SASM corresponds to weaker VIWVT over southern China and Japan.

The anomalous VIWVT related to the SVD2 mode features an anomalous cyclone over the SASM, and that over the EASM shows a zonally wavelike pattern between $20^{\circ}$ and $50^{\circ} \mathrm{N}$ with a strong anticyclonic VIWVT over the central EASM (Fig. 2). The wavelike VIWVT anomalies have three centers that zonally situate around $100^{\circ}, 125^{\circ}$, and $150^{\circ} \mathrm{E}$, respectively, over the midlatitudes of East Asia, which may be related to the teleconnection pattern along the westerly jet. The anomalous VIWVT over the ASM also shows high consistency to each other among the four datasets except that the anomalous westerly VIWVT differs slightly over the western North Pacific (WNP) (Fig. S2). The SVD2 mode is responsible for about $13.8 \%, 13.4 \%, 15.0 \%$, and $7.8 \%$ of the total squared covariance fraction described by the NCEP, JRA55, ERA40I, and ERA20C datasets, respectively. The SVD2 mode reveals a zonal connection of the VIWVT over the two monsoons and the associated time series of the VIWVT over the SASM (Fig. 2c) and EASM
(Fig. 2d) yield a correlation coefficient of beyond 0.74 for the four datasets (Table 2). Besides, it demonstrates an in-phase (out-of-phase) relationship between the VIWVT over southern SASM and northern China (Japan).

\section{b. Connections with the summer rainfall anomalies over the ASM}

The convergence/divergence of the VIWVT is directly related to the local rainfall. In this section, the summer rainfall anomalies over the ASM associated with the two SVD modes and the dynamical and thermal contributions by the wind divergence and moisture advection to the divergence/convergence of the VIWVT are explored. Given the high correlations between the SVD1_EASM/ SVD2_EASM and SVD1_SASM/SVD2_SASM, only the results associated with the two SVD modes over the EASM are used in the text. Consistent results are also achieved based on the two SVD modes over the SASM.

The rainfall anomalies related to the SVD1_EASM feature a tripole structure with significantly positive anomalies over the area $15^{\circ} \mathrm{S}-15^{\circ} \mathrm{N}$ and subtropical East Asia and negative anomalies over northern India, the South China Sea, and the tropical western North Pacific (Fig. 3a), which are largely attributed to the tripole divergence/convergence anomalies of the VIWVT associated with the SVD1_EASM (Fig. 3b). For the two monsoon regions, the rainfall anomalies over the India show a dipole pattern (south positive-north negative) while those over the East Asia exhibit a tripole pattern with positive center along the mei-yu belt and negative centers over the two flanks, corresponding well to the

TABLE 2. Correlation coefficients between the time series of SVD1_SASM (SVD2_SASM) and SVD1_EASM (SVD2_EASM) for the three datasets. All of the correlation coefficients exceed the 99.9\% confidence level based on the two-tailed Student's test.

\begin{tabular}{lll}
\hline \hline Datasets & SVD1 & SVD2 \\
\hline NCEP1 & 0.764 & 0.742 \\
ERA40I & 0.765 & 0.741 \\
JRA55 & 0.786 & 0.736 \\
ERA20C & 0.85 & 0.80
\end{tabular}


(a) PREC

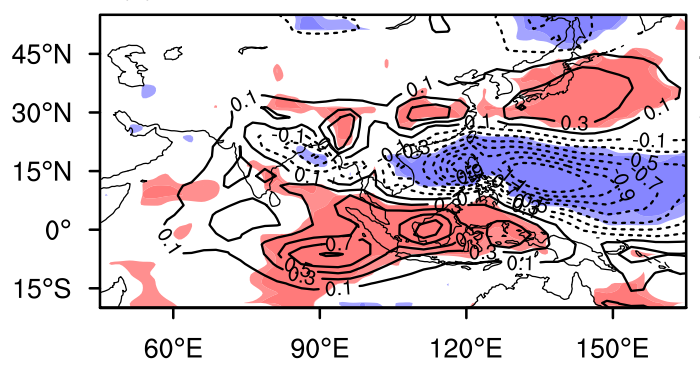

(c) Dynamical (wind divergence)

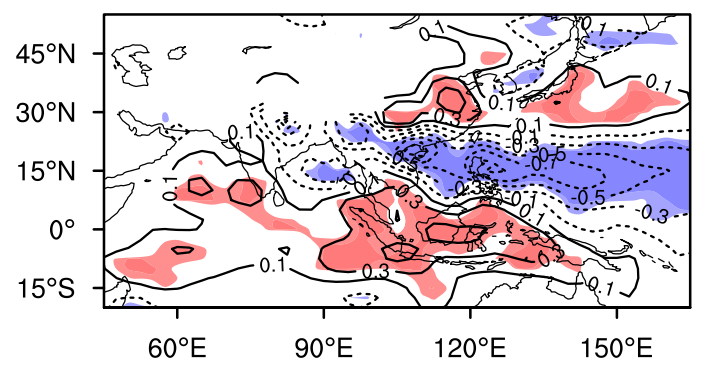

(b) Divergence of VIWVT

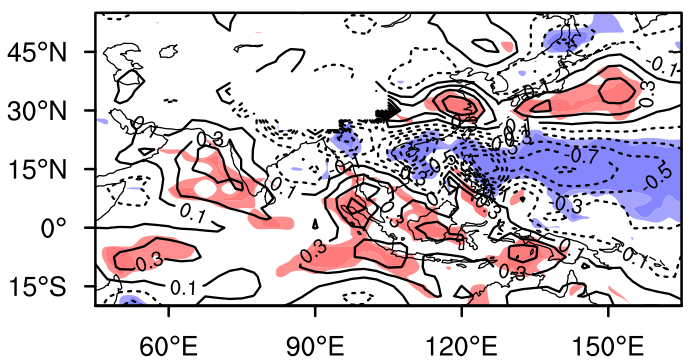

(d) Thermal (moisture advection)

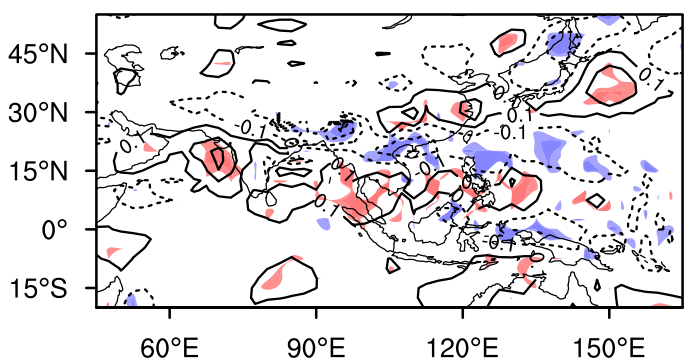

FIG. 3. Regressed anomalies of (a) summer precipitation (PREC) and (b) divergence of VIWVT, and its dynamical and thermal components contributed by (c) wind divergence and (d) moisture advection against the time series of to the SVD1_EASM (unit: $\mathrm{mm} \mathrm{day}^{-1}$ ). Shading denotes anomalies are significant beyond the $95 \%$ confidence level.

dipole and tripole VIWVT anomalies over the SASM and EASM, respectively (Fig. 1). Furthermore, up to $80 \%$ of the rainfall anomalies over the two monsoons, especially the EASM, result from the VIWVT divergence/convergence which is largely attributed to the wind divergence/ convergence (accounting for up to $80 \%$ of the total VIWVT divergence/convergence) except the western SASM where the moisture advection dominates (Figs. 3c,d).

As for the SVD2_EASM, the entire SASM is covered by significantly positive rainfall anomalies that are mainly caused by the VIWVT convergence (Figs. 4a,b). The rainfall anomalies over the EASM show a dipole pattern with negative anomalies over the southern EASM (along the mei-yu belt from upper Yangtze River valley to the Korean peninsula and Japan) and positive ones over the northern EASM (Fig. 4a), which result from the south divergence and north convergence (Fig. 4b) related to the zonal wavelike VIWVT over the EASM (Fig. 2). In addition, the VIWVT convergence anomalies over the SASM and southern EASM are mainly caused by the wind convergence but those over the northern EASM are a response to moisture advection. This is different from previous understanding that the local rainfall variation over the northern EASM is largely contributed by the wind divergence/convergence (Huang et al. 2017).

In relation to the rainfall anomalies over the two monsoons, the SVD2 mode indeed represents an in-phase/antiphase relationship between rainfall variations over the all-India and northern China/mei-yu belt, consistent with many previous works (Ha et al. 2017; Wu 2017; many others). While the SVD1 mode demonstrates an in-phase/antiphase relationship between rainfall variations over the southern/northern India and the mei-yu belt (Yangtze River valley and Japan), but this has received less attention in previous work. Besides, the variations of the rainfall anomalies in the SASM and meiyu belt associated with the two SVD modes indicate that one should be careful to interpret the connections of the summer rainfall over the two monsoons, which can also explain the spatial variation in the SASM rainfall associated with EASM precipitation index defined over the mei-yu belt $\left(25^{\circ}-40^{\circ} \mathrm{N}, 110^{\circ}-145^{\circ} \mathrm{E}\right)$ documented in Ha et al. (2017). Furthermore, given the complex features of the VIWVT and rainfall anomalies associated with the two SVD modes, studies on the linkages of the VIWVT/ rainfall variations over the two monsoons based on regional-mean VIWVT/rainfall to some extent capture a portion of the linkages between the two monsoons. For example, the study of Zhang (2001) portrays the meridional connection of the VIWVT over the two monsoons (SVD1 mode) and studies on how the in-phase variation of the summer rainfall over India and northern China captures the connection of the rainfall variation associated with the SVD2 mode. From this aspect, the present study on the linkages of the leading two modes of the VIWVT over the two monsoons may obtain a more 
(a) PREC

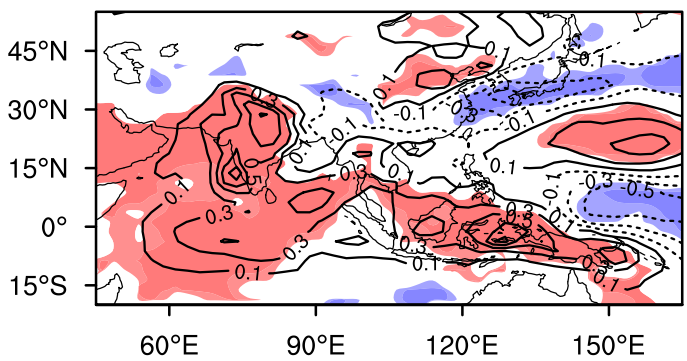

(c) Dynamical (wind divergence)

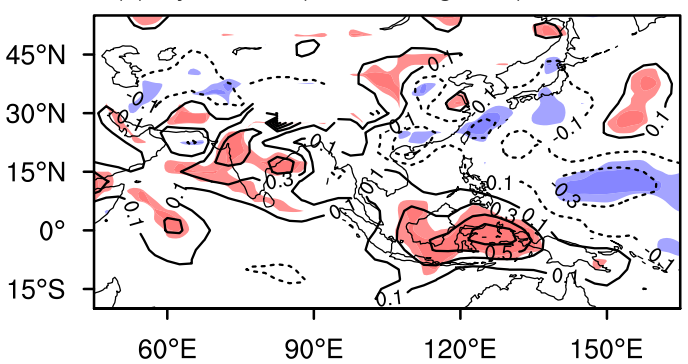

(b) Divergence of VIWVT

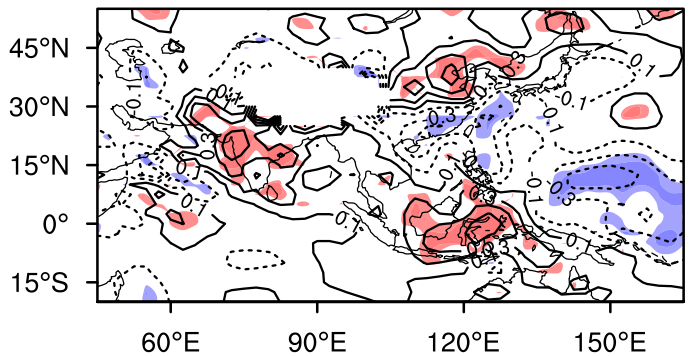

(d) Thermal (moisture advection)

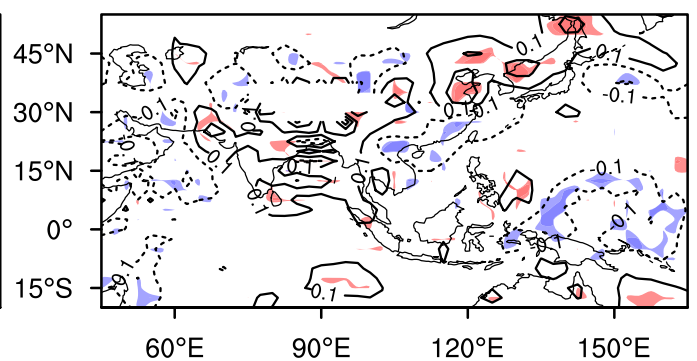

FIG. 4. As in Fig. 1, but for SVD2_EASM.

comprehensive understanding of the SASM-EASM connections.

\section{c. Pathways for the linkages of the VIWVT over the $S A S M$ and EASM}

As indicated in previous works, the atmospheric circulation changes play an essential role in linking the summer rainfall variations over the Indian monsoon and EASM. As for the two SVD modes, the associated atmospheric circulation anomalies are investigated and the results related to the two SVD modes over the EASM are provided in this section.

Figure 5 displays the anomalous 850-hPa winds and 500hPa GPH related to the SVD1_EASM and SVD2_EASM.
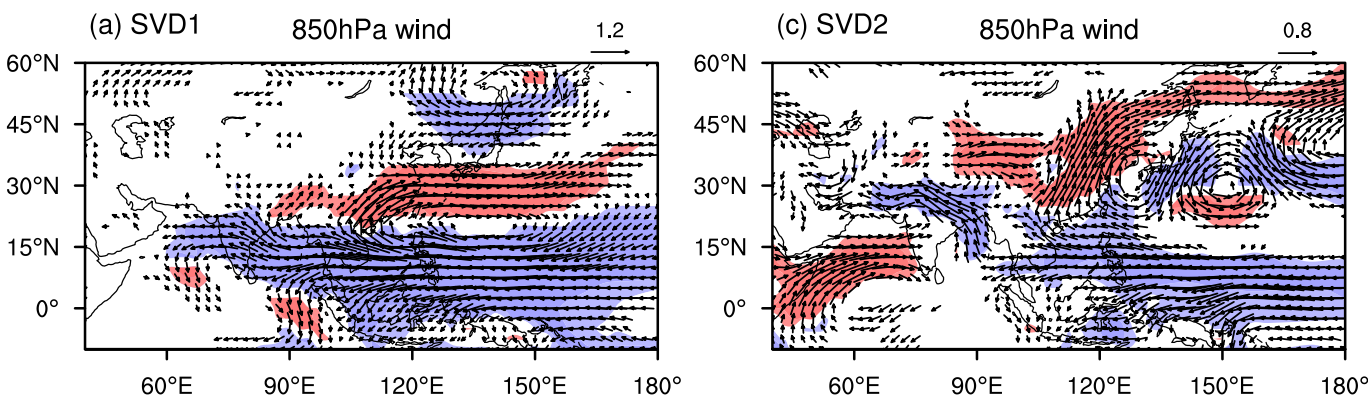

(b) SVD1 500hPa GPH

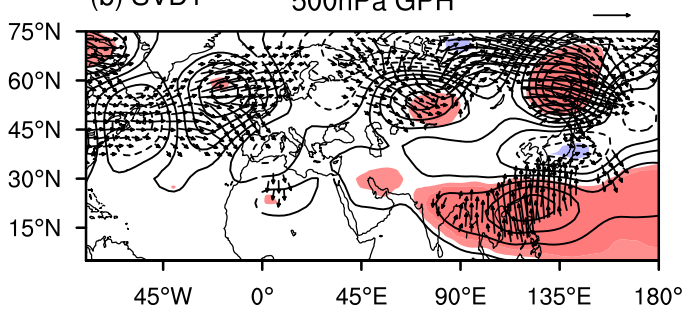

(d) SVD2

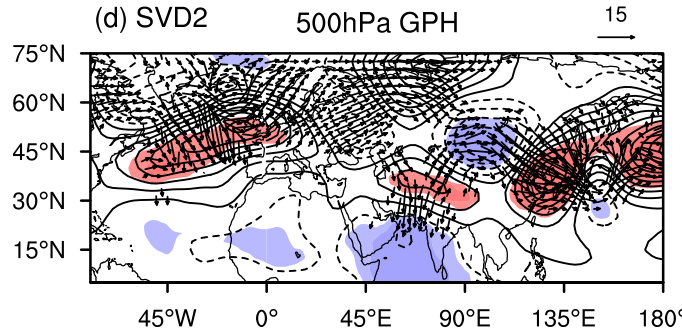

FIG. 5. Regressed anomalies of the (a),(c) 850-hPa winds (unit: $\mathrm{m} \mathrm{s}^{-1}$ ) and (b),(d) 500-hPa geopotential height $(\mathrm{GPH})$ along with the wave activity flux (Takaya and Nakamura 2001) against the time series of the (left) SVD1_ EASM and (right) SVD2_EASM. Shading denotes anomalies are significant beyond the $95 \%$ confidence level. Only the vectors significant beyond the $80 \%$ confidence level are plotted. 
TABLE 3. Correlation coefficients of the time series of SVD1_ SASM/SVD1_EASM, and WNPSH index with Niño-3.4, IOBM, and WNPSH indices. One (*), two (**), and three (***) asterisks indicate significance at the $90 \%, 95 \%$, and $99 \%$ confidence level, repectively.

\begin{tabular}{lcc}
\hline \hline \multicolumn{1}{c}{ Indices } & SVD1 (SASM/EASM) & WNPSH \\
\hline Niño-3.4 DJF(0) & $-0.446 * * /-0.475^{* * *}$ & $0.555^{* * * *}$ \\
Niño-3.4 JJA(0) & $0.240 * / 0.271^{* *}$ & -0.084 \\
IOBM JJA(0) & $-0.437 * * * /-0.464 * * *$ & $0.459 * * *$ \\
Niño-3.4 DJF(1) & $0.396 * * / 0.414 * * *$ & $-0.238^{*}$ \\
WNPSH & $-0.603 * * * /-0.799 * * *$ & - \\
\hline
\end{tabular}

The anomalous low-level winds over the ASM are characterized by an anomalous cyclone over the southern SASM (northern EASM) and an anomalous anticyclone over the northern SASM (southern EASM), showing high similarity to the VIWVT anomalies in SVD1 mode (Fig. 5a). The anomalous anticyclone over the southern EASM extends westward to northern SASM and is closely associated with the anomalous WNPSH. This is supported by the significant correlations exceeding -0.603 and -0.799 between the WNPSH index and the time series of the SVD1_SASM and SVD1_EASM, respectively (Table 3). The anomalous anticyclone over the southern EASM features a Kelvin wave response to the atmospheric heating over the tropical Indian Ocean (abovenormal rainfall in Fig. 3a), which suppresses the rainfall over the SCS-WNP (Fig. 3a) and in turn induces an anomalous cyclone to its north through a Rossby wave forcing, revealing a typical EAP/PJ teleconnection pattern in the $850-\mathrm{hPa}$ winds and $500-\mathrm{hPa}$ GPH anomalies over the EASM (Figs. 5a,b) that are similar to previous findings (Nitta 1987; Hirota and Takahashi 2012; Kamae et al. 2014; Wakabayashi and Kawamura 2004). It can be concluded that the anomalous anticyclone over the WNP or the WNPSH plays an essential role in the VIWVT linkages associated with the SVD1 mode, which involves the modification of the SASM on the WVT to the EASM through changing the anomalous circulation over the southern EASM and WNP region. This is consistent with the south pathway defined in $\mathrm{Wu}$ (2017) through which the SASM links to the EASM.

The anomalous $850-\mathrm{hPa}$ winds associated with the SVD2 mode reveal an anomalous cyclone over the SASM and wavelike wind anomalies over the EASM (Fig. 5c), resembling the VIWVT anomalies in SVD2 mode (Fig. 2). In the midlevel, the 500-hPa GPH anomalies exhibit a CGT pattern (Fig. 5d) propagating along the westerly jet. This teleconnection pattern exhibits a response to the anomalous heating over the SASM and North Atlantic Ocean. For instance, the negative 500-hPa GPH anomalies to the northwest of
TABLE 4. Correlation coefficients of the time series of SVD2 SASM/SVD2_EASM and CGT index with Niño-3.4, NAT, and CGT indices. One $(*)$, two $(* *)$, and three $(* * *)$ asterisks indicate significance at the $90 \%, 95 \%$, and $99 \%$ confidence level, repectively.

\begin{tabular}{|c|c|c|}
\hline Indices & SVD2 (SASM/EASM) & CGT \\
\hline Niño-3.4 DJF(0) & $-0.137 /-0.226^{*}$ & 0.134 \\
\hline Niño-3.4 JJA(0) & $0.345 * * / 0.444 * * *$ & $-0.348^{* *}$ \\
\hline NAT JJA(0) & $-0.369 * * * /-0.375 * * *$ & $0.236^{*}$ \\
\hline Niño-3.4 DJF(1) & $-0.211 /-0.419 * * *$ & $-0.338 * *$ \\
\hline CGT & $-0.649 * * * /-0.647 * * *$ & - \\
\hline
\end{tabular}

SASM show a Rossby wave-type response to the anomalous heating over the SASM (Figs. 4a and 5d), while the positive 500-hPa GPH anomalies over the North Atlantic Ocean may be related to the anomalous local heating (Figs. 4a and 5d). The correlations between the CGT index and the time series of the SVD2_SASM and SVD2_EASM exceed -0.649 and -0.647 , respectively (Table 4). These results suggest that this teleconnection pattern is a key factor linking the VIWVT in the SVD2 mode, similar to previous studies on the connections of the summer rainfall over India and north China (Lu et al. 2002; Wu 2002; many others).

To sum up, the above analyses based on the four datasets consistently reveal two coupled modes of the VIWVT over the SASM and EASM, which together explain about $90 \%$ of the total squared covariance fraction of the VIWVT over the two monsoons. The first coupled mode depicts a meridional coupling between dipole VIWVT anomalies over both the SASM and EASM, which actually mirrors an impact of the SASM on the EASM by modifying the WVT to the EASM through changing the circulation anomalies over the WNP. The second coupled mode manifests a zonal coupling between an anomalous anticyclonic WVT over the SASM and an anomalous wavelike WVT over the EASM, and indicates an impact of the SASM on the EASM that is operated via the CGT pattern.

\section{Role of ENSO in the linkages of the VIWVT over the SASM and EASM}

The variability of the SASM and EASM shows close association with tropical Indo-Pacific SST anomalies (Ding 2007; Kripalani and Kulkarni 1997; Lau and Wu 2001; Lau et al. 2000; Xie et al. 2016). The SASMEASM connections have also been attributed to the impacts of the tropical Indo-Pacific Ocean (TIPO) SSTAs, such as ENSO, IODM, and IOBM (Ha et al. 2017; Wu 2017). Through further analysis, we found that the SSTAs over the TIPO and North Atlantic Ocean 

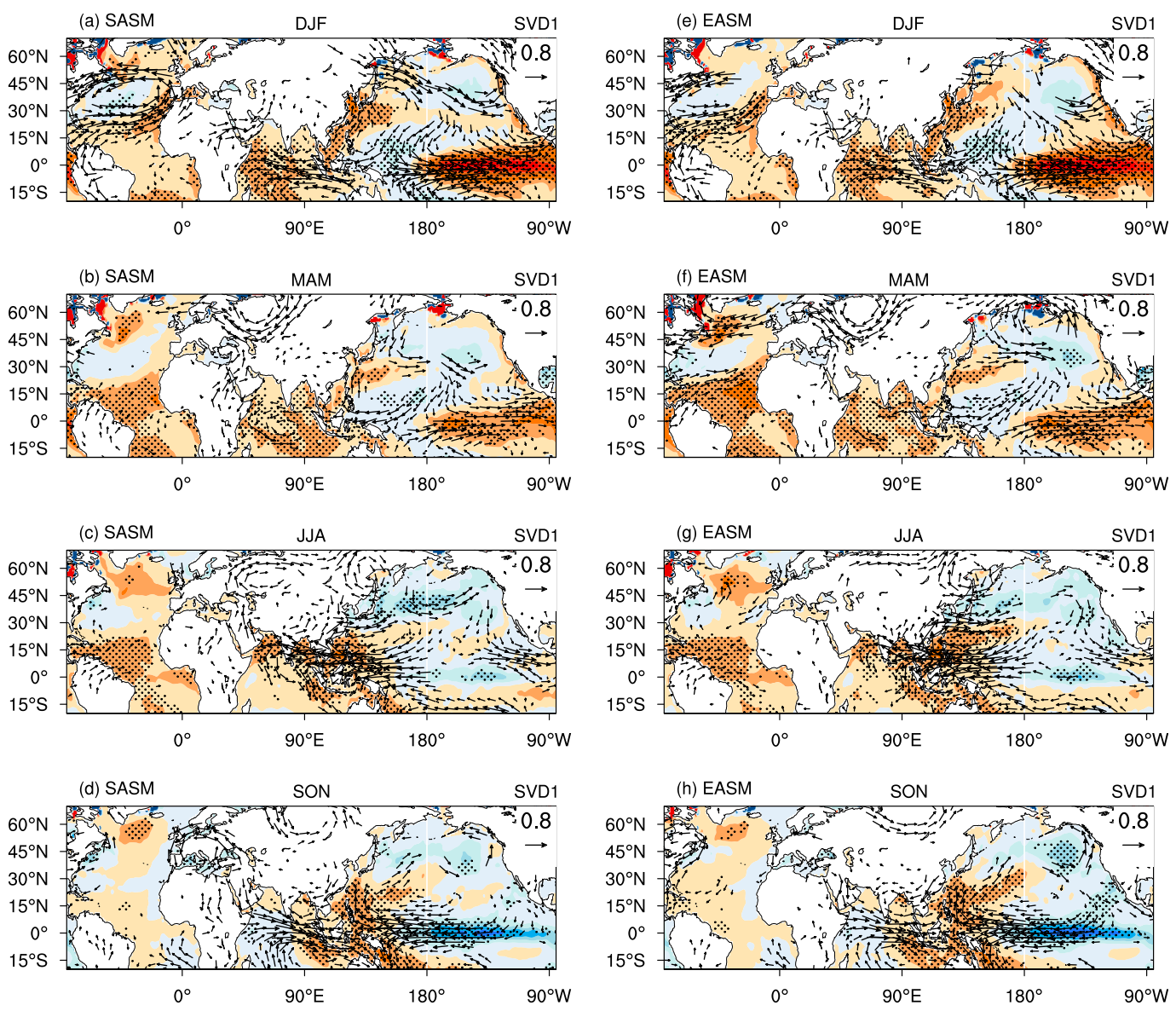

$\begin{array}{ccccccccccccc}-0.6 & -0.5 & -0.4 & -0.3 & -0.2 & -0.1 & 0 & 0.1 & 0.2 & 0.3 & 0.4 & 0.5 & 0.6\end{array}$

FIG. 6. Regressed anomalies of the seasonal mean (DJF, MAM, JJA, and SON) SST (shading; unit: K) and 850$\mathrm{hPa}$ winds (vector; unit: $\mathrm{m} \mathrm{s}^{-1}$ ) against the time series of the (left) SVD1_SASM and (right) SVD1_EASM. Stippling denotes the SSTAs significant beyond $90 \%$ confidence level. Only vectors with anomalies significant beyond the $90 \%$ confidence level are plotted.

exert crucial impacts on the coupling of the VIWVT over the two monsoons.

\section{a. The SVD1 mode: ENSO phase transition}

Figure 6 displays the anomalous SST and $850-\mathrm{hPa}$ winds regressed against the time series of SVD1_SASM and SVD1_EASM. Note that the positive phase of the SVD1 (SVD1_SASM and SVD1_EASM) mode preferentially occurs during the El Niño to La Niña transition phase, which is accompanied by significant IOBM SST warming from winter to summer. The IOBM SST warming during summer is regarded as a delayed response to remote El Niño forcing through the atmospheric bridge (Lau and Wu 2001; Xie et al. 2009; Zhang et al. 1999). The relationships of the SVD1 mode with the ENSO and IOBM are also achieved by a lag correlation analysis between the time series of the SVD1 mode and Niño-3.4 index and IOBM index (Figs. 7a,b). The SVD1_SASM and SVD1_EASM show remarkably large correlations with Niño-3.4 index in $\mathrm{D}(-1) \mathrm{JF}$ and IOBM index in JJA( 0 ) but weak correlations with Niño3.4 in $\operatorname{JJA}(0)$ (listed in Table 3), suggesting dominant roles of the decaying phase of ENSO and weaker impact of the central-eastern Pacific SST cooling in JJA(0) on the SVD1 mode.

As indicated above, the anomalous WNPSH or anticyclone/cyclone over the WNP plays an important role in the SVD1 mode, which is also closely related to the ENSO cycle. With respect to the SVD1 mode, an anomalous anticyclone emerges over the WNP during the preceding winter and persists into summer with enhanced intensity, showing a response to the decaying phase of El Niño. The enhancement of its intensity in summer is attributed to the IOBM SST warming (in 
(a) Nino-3.4

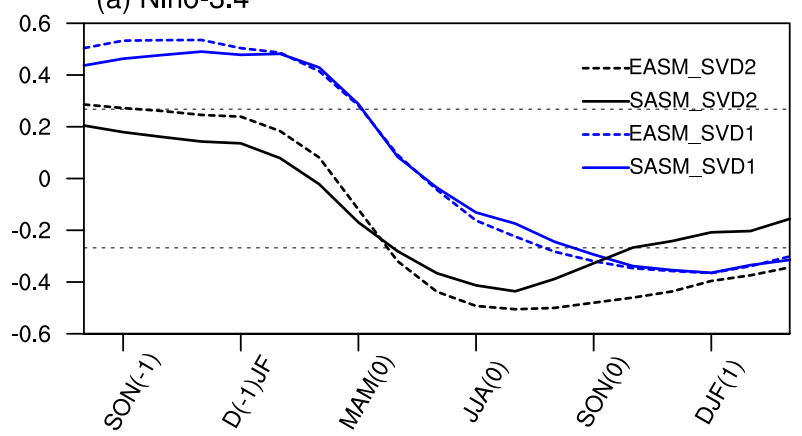

(b) IOBM

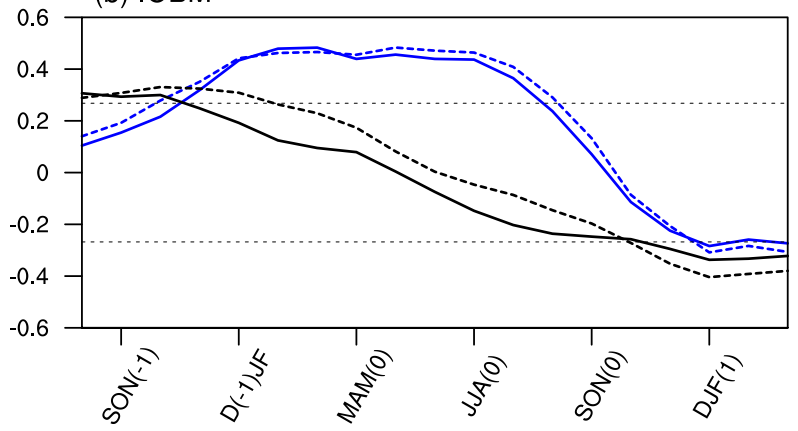

FIG. 7. Lagged correlation of the time series of SVD1 and SVD2 over the SASM and EASM with the (a) Niño-3.4 index and (b) IOBM index. Blue solid (dashed) line is SVD1_SASM (SVD2_ SASM) and black solid (dashed) is SVD1_EASM (SVD2_EASM). Numbers in parentheses denote years relative to SVD1 or SVD2 mode: 0 is for its simultaneous years; -1 and 1 are for the preceding and following years. Dashed horizontal line is correlation values beyond the $95 \%$ significant confidence level.

particular the SSTAs over the north Indian Ocean) forcing through a Kelvin wave response named the capacitor mechanism by Xie et al. (2009). These results are supported by the correlation analyses (listed in Table 3 ) that the anomalous WNPSH (denoted by the WNPSH index) has significant correlations of beyond 0.555 and 0.459 with the Niño-3.4 index during $\mathrm{D}(-1) \mathrm{JF}$ and the IOBM index during JJA(0). In addition, the anomalous anticyclone also reveals lower correlations with the Niño3.4 index during $\operatorname{JJA}(0)$ and $\operatorname{DJF}(1)$. This means that the weak SST cooling over central-eastern tropical Pacific during summer that is related to the developing phase of El Niño may partially contribute to the anomalous cyclone over the WNP via a Rossby wave-type response. These results support the finding of Lau and Wu (2001) that the strong ASM-ENSO relation tends to occur during the transition phases of El Niño and La Niña.

\section{b. The SVD2 mode: ENSO developing phase}

The SSTAs related to the SVD2 mode over the tropical Pacific Ocean resemble the features associated with the developing phase of La Niña (Fig. 8). The SVD2_SASM and SVD2_EASM have the largest correlations with the Niño-3.4 index during summertime (JJA and August-October) but that weaken evidently in the following winter in particular for the SVD2_SASM (Fig. 7 and Table 4). This means that the developing phase of ENSO may be not a necessary condition for the SVD2 mode. The SSTAs over the North Atlantic Ocean that feature an evidently tripole pattern may also contribute to the SVD2 mode by triggering the wavelike circulation over Eurasia (Zheng et al. 2016). For simplicity, we define a North Atlantic tripole index (NATI) to express the tripole SSTAs, which is constructed as $\mathrm{NATI}=[\mathrm{SSTA}]_{\mathrm{C}}-0.5 \times[\mathrm{SSTA}]_{\mathrm{N}}-0.5 \times[\mathrm{SSTA}]_{\mathrm{S}}$, where $[\mathrm{SSTA}]_{\mathrm{C}},[\mathrm{SSTA}]_{\mathrm{N}}$, and $[\mathrm{SSTA}]_{\mathrm{S}}$ denote the SSTA averaged over the regions of $\left(35^{\circ}-45^{\circ} \mathrm{N}, 30^{\circ}-\right.$ $\left.60^{\circ} \mathrm{W}\right),\left(55^{\circ}-65^{\circ} \mathrm{N}, 20^{\circ}-45^{\circ} \mathrm{W}\right)$, and $\left(10^{\circ}-25^{\circ} \mathrm{N}, 50^{\circ}-\right.$ $75^{\circ} \mathrm{W}$ ), respectively. The NAT index has significant correlations of $-0.369,-0.375$, and 0.236 with the time series of the SVD2_SASM, SVD2_EASM, and the CGT index, respectively (listed in Table 4), confirming the significant impact of the NAT on the SVD2 mode.

Furthermore, the summer VIWVT anomalies associated with the decaying and developing phases of ENSO, simultaneous IOBM, and NAT SSTAs are also explored. As shown in Figs. 9a and 9b, both the VIWVT anomalies regressed against the Niño-3.4 index in $\mathrm{D}(-1) \mathrm{JF}$ and the IOBM index in $\mathrm{JJA}(0)$ show large similarity to the VIWVT anomalies related to the SVD1 mode, except that the anticyclonic VIWVT anomalies over the southern EASM in Fig. 9a are northward situated in contrast to that related to the SVD1 mode and in Fig. 9b. These differences may be attributed to the IOBM's capacitor role in linking the ENSO and ASM VIWVT. The VIWVT anomalies regressed against the simultaneous Niño-3.4 (multiplied by -1 ) and NAT indices also resemble the VIWVT anomalies in SVD2 mode (Figs. 9c,d), showing a clearly zonal coupling pattern of the VIWVT over the two monsoons. These results confirm the above findings of the significant roles of the ENSO phase transition and developing phase on the meridional and zonal connections of the VIWVT over the SASM and EASM, respectively.

\section{Interdecadal changes in the linkages of the VIWVT over the two monsoons}

Numerical investigators have pointed out the interdecadal changes in the tropical Pacific/Indian Ocean SSTAs (Chowdary et al. 2014b) and their relationship with the two monsoons (Ding et al. 2010; Wu and Wang 2002; Hu et al. 2013) around the late 1970s, which are also accompanied by an enhanced ENSO-IOBM 

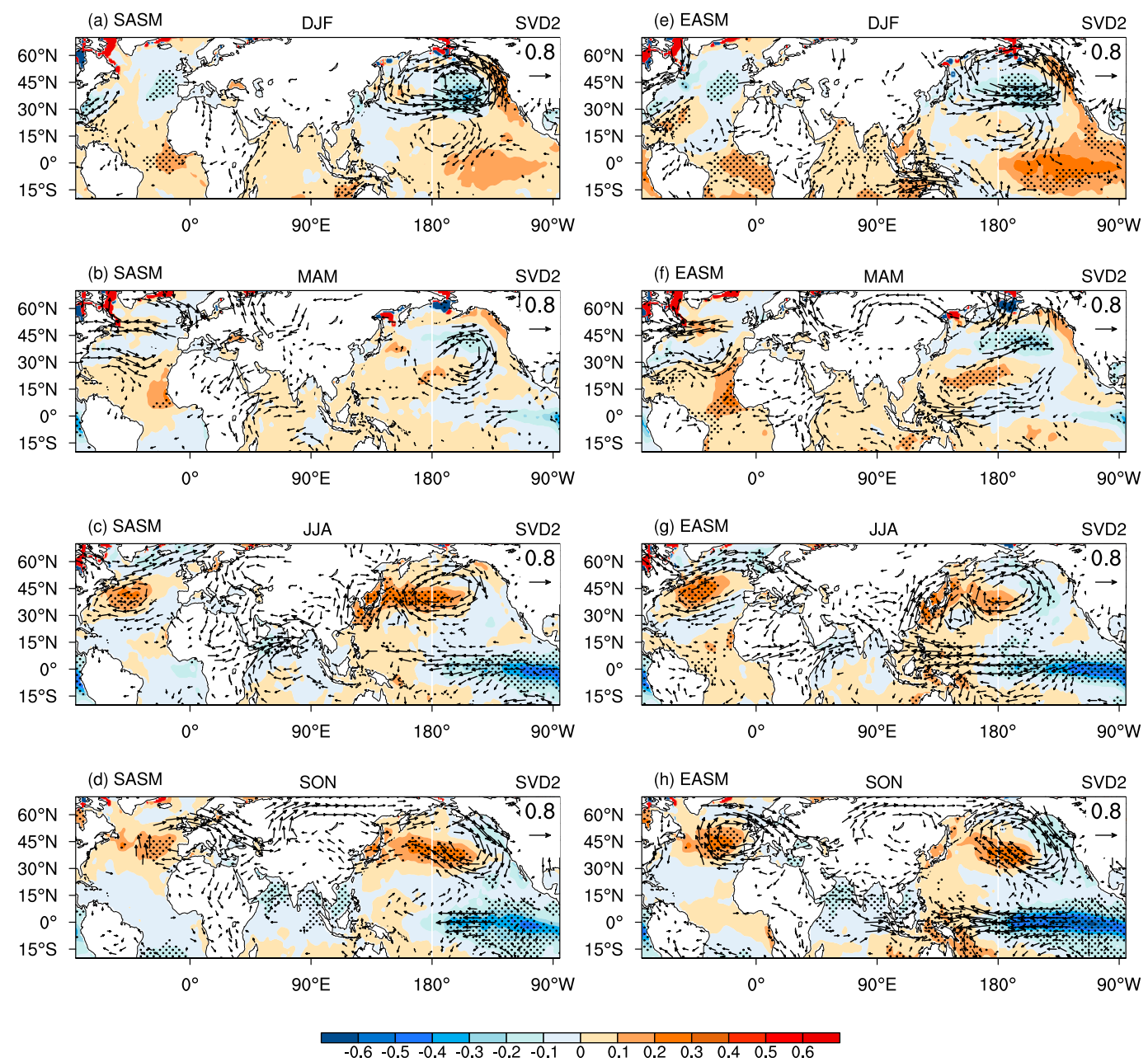

FIG. 8. As in Fig. 6, but for (left) SVD2_SASM and (right) SVD2_EASM.

relationship (Xie et al. 2010; Tao et al. 2015), a significant shift of the WNPSH (He and Gong 2002; Park et al. 2010), and the CGT pattern (Wang et al. 2012; Wang et al. 2017). These changes of the key factors affecting the ASM could strongly modulate the connections of the VIWVT over the two monsoons. Thus, the features and possible causes associated with the changes in their connections are primarily discussed in this section.

The changes in the connections of the VIWVT associated with the two SVD modes are detected by calculating the 15-yr running correlations between the time series of SVD1_EASM (SVD2_EASM) and SVD1_ SASM (SVD2_SASM). As shown in Fig. 10a, the connection of the VIWVT over the two monsoons related to the SVD1 mode (meridional connection) reveals significant intensification since the late 1970s that are highly consistent among the four datasets. While the evolutions of the connection of the VIWVT related to the SVD2 mode (zonal connection) differ evidently among the four datasets, they consistently reveal a relatively strong connection prior to the early 1980s and after the mid-1990s and a weak connection during the 1980s (Fig. 10b), similar to the relationship variations between Indian and northern China rainfall (Wu 2017; many others) or EASM summer rainfall [defined over the domain $25^{\circ}-40^{\circ} \mathrm{N}, 110^{\circ}-145^{\circ} \mathrm{E}$ in Ha et al. (2017)]. In fact, the VIWVT pattern during the strong connection periods demonstrates the robust coupling pattern of the VIWVT over the two monsoons related to each SVD mode. These results are confirmed by the spatial variations of the VIWVT anomalies corresponding to the two SVD modes during the three periods P1 (1961-79), P2 (1980-91), and P3 (1995-2005) using NCEP1 (Fig. S3).

As the SVD1 mode over the two monsoons shows close association with the ENSO/IOBM and WNPSH, the variation of their connections may be modulated by the changes in the impacts of ENSO/IOBM on the two monsoons or the changes of the WNPSH. By 
(a) Nino3.4_D(-1)JF

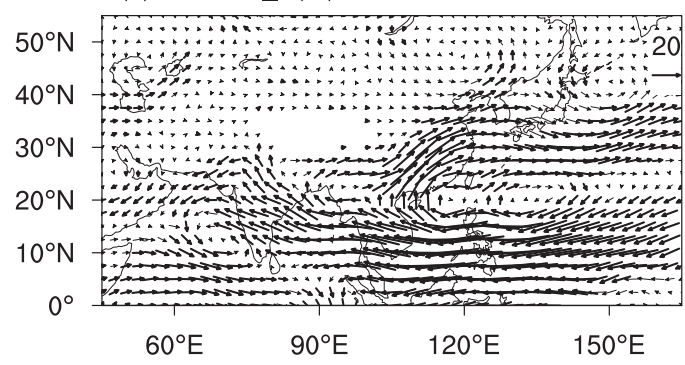

(b) IOBM_JJA(0)

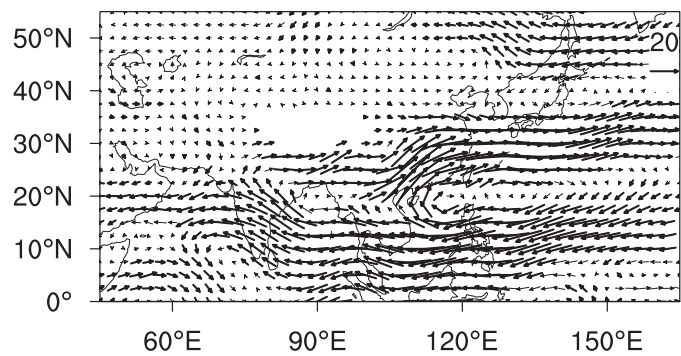

(c) -Nino3.4_JJA(0)

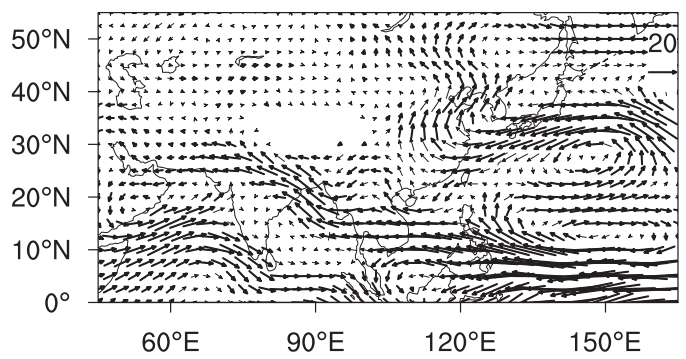

(d) NAT_JJA(0)

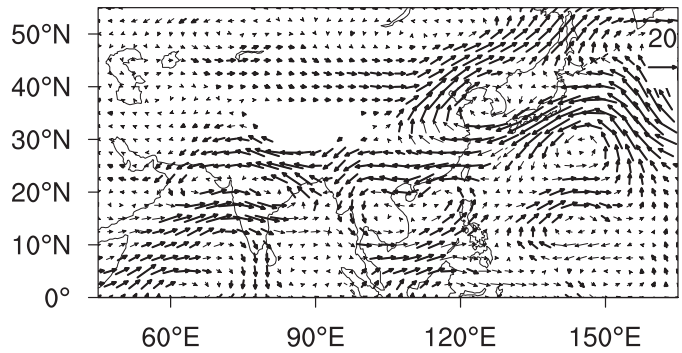

FIG. 9. Regressed anomalies of summer VIWVT (unit: $\mathrm{kg} \mathrm{m}^{-2} \mathrm{~s}^{-1}$ ) against the (a) Niño-3.4 index in preceding winter $\mathrm{D}(-1) \mathrm{JF}$ and (c) Niño-3.4 index in simultaneous summer (multiply by -1), and (b) IOBM and (d) NAT indices in simultaneous summer. Vectors with anomalies significant beyond the $90 \%$ confidence level are bolded.

performing a 15-yr running correlation analysis between the Niño-3.4 index in preceding winter, IOBM index, and WNPSH index in simultaneous summer and the time series of the SVD1_EASM and SVD1_SASM, we find that the intensified connection of the VIWVT over the EASM and SASM (SVD1 mode) is attributed to the coherent enhancement in the relationship with the WNPSH since the late 1970s (Fig. 11a), which may be modulated by the intensified impacts of the preceding ENSO and simultaneous IOBM on the EASM and SASM after the late 1970s (Figs. 11b,c). The interdecadal southwestward located WNPSH after the late 1970s may also favor the meridional connection of the VIWVT over the two monsoons (He and Gong 2002).

Likewise, the correlation evolutions of the summer Niño-3.4 index, NAT index, and CGT index with the time series of the SVD2_EASM and SVD2_SASM are investigated in Fig. 12. It is found that the changes in the zonal connection of the VIWVT over the two monsoons (SVD2 mode) are modulated by the changes in the relationship of the CGT with two monsoons, in particular the relationship with SASM (Fig. 12a) that leads to the interdecadal changes of the zonal connections of the VIWVT. The weakened CGT-SASM relationship around the late 1970 s is caused by the weakened connection of the CGT with the anomalous heating over the SASM (figure not shown). This may be also associated with the weakened impact of ENSO on the SASM (Fig. 12b) and the interdecadal changes in the CGT around the late 1970s documented in previous findings (Wu and Wang 2002; Wang et al. 2017). The reintensified zonal connection of the VIWVT over the two monsoons after the mid-1990s corresponds to the restrengthening CGT-SASM relationship (Fig. 12a), but no evident signals are found in the SSTAs (figure not shown). One possible cause may be related to the interdecadal decreasing of all Indian monsoon rainfall (Figs. 9 and 10 in Huang et al. 2017) that favors the CGT-SASM connection. The enhanced CGT-SASM connection since the mid-1990s may be also another cause for the recent intensification of the South and East Asian monsoon contrast reported in Yun et al. (2014).

\section{Summary and discussion}

The present study investigates the linkages between the SASM and EASM from a WVT perspective, and has identified two coupled modes of the VIWVT over the two monsoons using the SVD method that account for above $90 \%$ of the total squared covariance fraction of the VIWVT over the SASM and EASM and are highly consistent among four reanalysis datasets. The corresponding processes and possible roles of the SSTAs related to the coupling of the VIWVT over the two monsoons as well as the changes in their linkages are explored. The main results are summarized as follows.

The SVD1 mode depicts a meridional connection of the VIWVT over the SASM and EASM, representing the 
(a) SASM-EASM(SVD1)

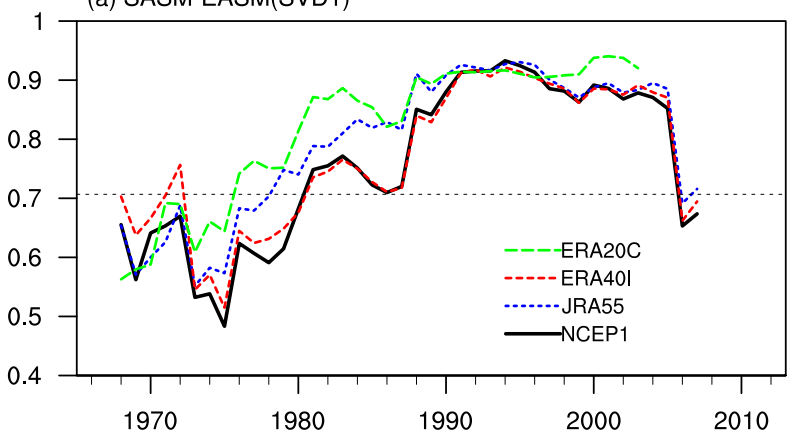

(b) SASM-EASM(SVD2)

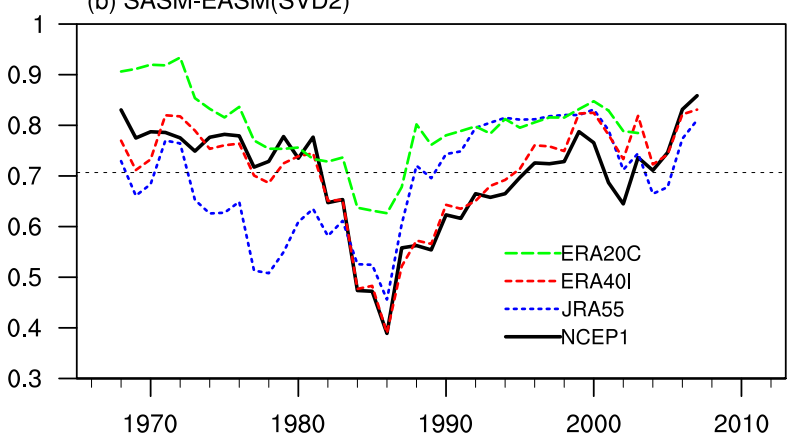

FIG. 10. The 15-yr running correlations between the time series of (a) the SVD1_SASM and SVD1_EASM and (b) the SVD2 SASM and SVD2_EASM for the NCEP1 (solid black), JRA55 (dotted blue), ERA40I (dotted red), and ERA20C (dotted green) datasets. The dashed horizontal line denotes the values with $95 \%$ significant confidence level.

coupling between the meridional dipole VIWVT anomalies over the SASM (south cyclone-north anticyclone) and EASM (south anticyclone-north cyclone). It explains about $75 \%$ of the total squared covariance fraction of the WVT over the two monsoons, and mirrors an impact of the SASM on the EASM by modifying the WVT to the EASM and the anomalous circulation over the WNP. The anomalous WNPSH plays an important role in linking the VIWVT over the SASM and EASM in the SVD1 mode. This mode is also corresponding to the outof-phase relationship between the meridional dipole precipitation anomalies over both the SASM and EASM. Statistical analysis indicates that the SVD1 mode is primarily attributed to the impact of the transition phase of ENSO that includes strong impacts of the decaying phase of El Niño/La Niña and summer IOBM SST warming/ cooling and weak impact of the summer central-eastern Pacific SST cooling/warming on the ASM. The simultaneous IOBM SST warming/cooling plays a critical role in linking the decaying phase of ENSO with the ASM WVT. Owing to the enhanced impacts of the ENSO and IOBM on the EASM and SASM around the late 1970s, the meridional connection of the VIWVT over the two monsoons (SVD1 mode) has intensified. (a) WNPSH

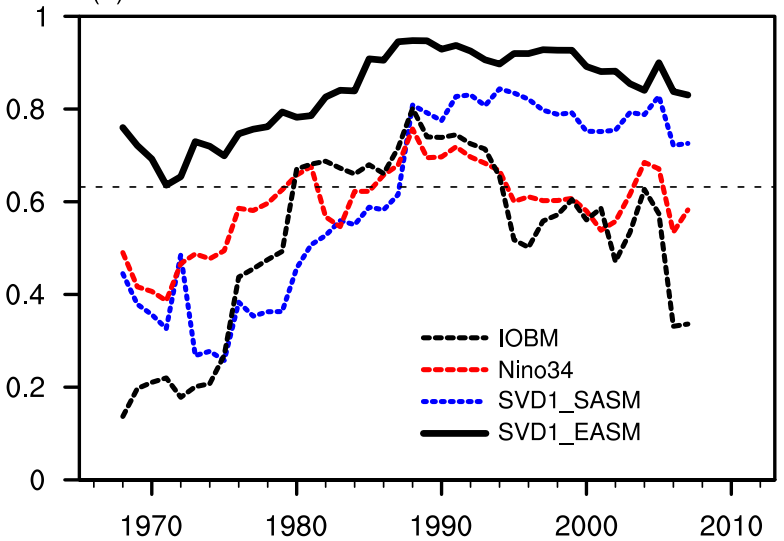

(b) Nino34

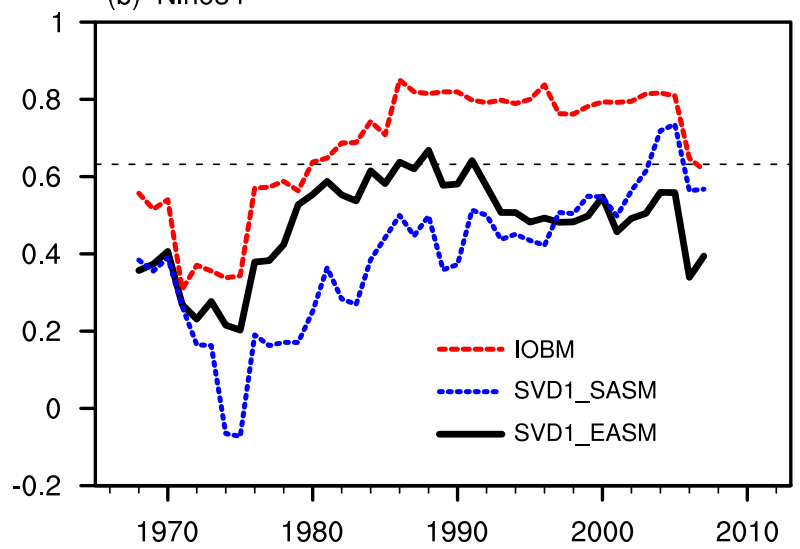

(c) IOBM

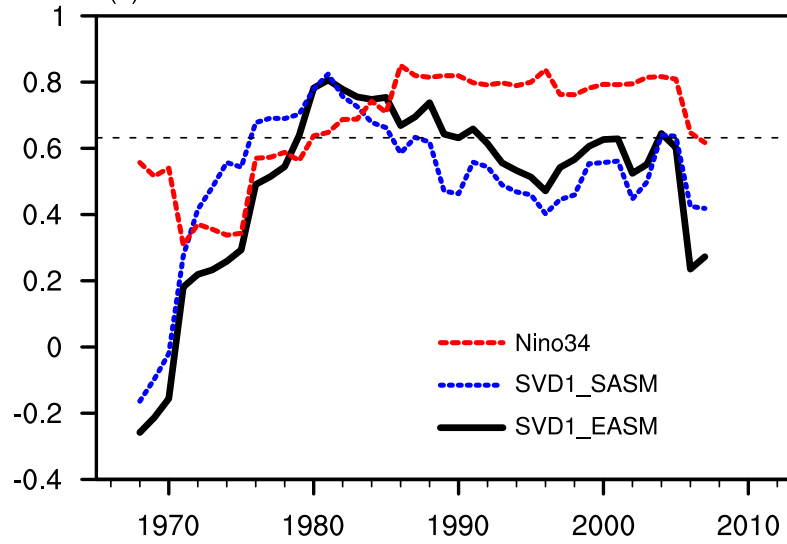

FIG. 11. The 15-yr running correlations of the (a) WNPSH index with the time series of SVD1_EASM, SVD1_SASM, Niño-3.4 $[\mathrm{D}(-1) \mathrm{JF}]$, and IOBM, (b) the Niño-3.4 index [D(-1)JF] with the time series of SVD1_EASM, SVD1_SASM, and IOBM(JJA), and (c) the IOBM index with the time series of SVD1_EASM, SVD1_ SASM, and Niño-3.4 [D(-1)JF]. The dashed horizontal line denotes the values with $95 \%$ significant confidence level. 
(a) CGT

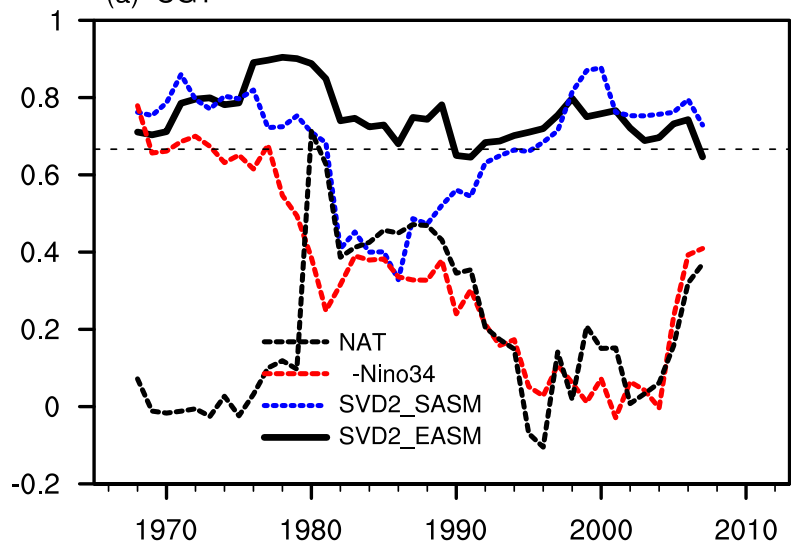

(b) -Nino34

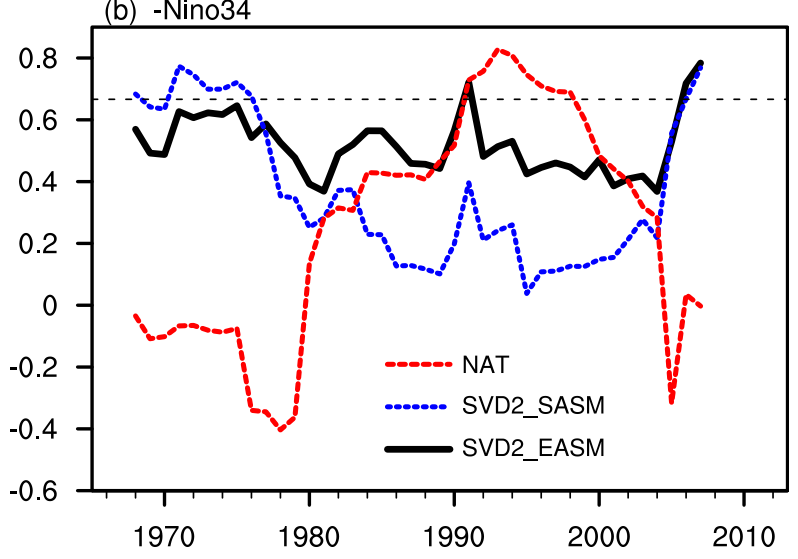

(c) NAT

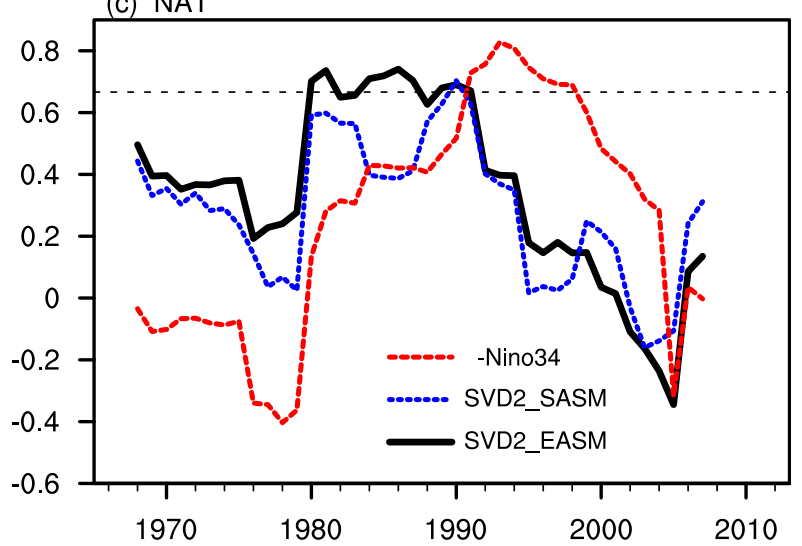

FIG. 12. The 15-yr running correlations of the (a) CGT index with the time series of SVD2_EASM, SVD2_SASM, Niño-3.4 (JJA), and NAT (JJA), (b) the Niño-3.4 index (JJA) with the time series of SVD2_EASM, SVD2_SASM, and IOBM (JJA), and (c) the NAT index (JJA) with the time series of SVD2_EASM, SVD2_SASM, and Niño-3.4 (JJA). The dashed horizontal line denotes the values with $95 \%$ significant confidence level.
The SVD2 mode presents a zonal connection of the VIWVT over the SASM and EASM and manifests the coupling of an anomalous cyclonic VIWVT over the SASM and an anomalous wavelike VIWVT over the EASM, which accounts for about $15 \%$ of the total squared covariance fraction of the VIWVT over the two monsoons. It indicates an impact of the SASM on the EASM through the CGT pattern and is responsible for the in-phase (out-ofphase) relationship between precipitation anomalies over all India and northern China (South Korea and Japan). The SVD2 mode is mainly attributed to the impacts of the developing phase of ENSO and simultaneous NAT SSTAs. The zonal connection of the VIWVT over the two monsoons (SVD2 mode) reveals significant weakening during the 1980s that is modulated by the changes in the CGTSASM relationship.

Previous studies have also indicated the roles of the IODM and Eurasian snow cover on the connections between the SASM and EASM. And they documented that the IODM in fall can be affected by the SASM and then exerts a delayed impact on the EASM. The IODM in fall acts as a bridge on the delayed relationship between the SASM and EASM, which may be carried out by the Eurasian snow (Kripalani et al. 2010). As for the coupling of the VIWVT over the SASM and EASM, the IODM in preceding fall also has significant correlations with the SVD1_SASM and SVD1_EASM (figure not shown), but it seems to be largely related to the ENSO phase transition.

Although the key processes related to the two SVD modes in particular the SVD2 mode are similar to previous findings based on regional-mean VIWVT or precipitation, in view of the spatial-temporal complexity of the two monsoons, the present study provides a WVT perspective on the SASM-EASM connections that promotes a comprehensive understanding on the SASMEASM connections and may have useful implications for seasonal climate prediction of the ASM.

Acknowledgments. This study is jointly supported by the National Key Research and Development Program (Grant 2016YFA0600603), the National Natural Science Foundation of China (Grants 41605058, 41530425, and 41831175), and the Fundamental Research Funds for the Central Universities.

\section{REFERENCES}

Chen, M., P. Xie, J. E. Janowiak, and P. A. Arkin, 2002: Global land precipitation: A 50-yr monthly analysis based on gauge observations. J. Hydrometeor., 3, 249-266, https://doi.org/ 10.1175/1525-7541(2002)003<0249:GLPAYM>2.0.CO;2.

Choi, K.-S., and Coauthors, 2014: A study of teleconnection between the South Asian and East Asian monsoons: Comparison of summer monsoon precipitation of Nepal and South Korea. 
J. Environ. Sci. Int., 23, 1719-1729, https://doi.org/10.5322/ JESI.2014.23.10.1719.

Chowdary, J. S., H. S. Chaudhari, C. Gnanaseelan, A. Parekh, A. S. Rao, P. Sreenivas, S. Pokhrel, and P. Singh, 2014a: Summer monsoon circulation and precipitation over the tropical Indian Ocean during ENSO in the NCEP Climate Forecast System. Climate Dyn., 42, 1925-1947, https://doi.org/10.1007/s00382013-1826-5.

_ A. Parekh, C. Gnanaseelan, and P. Sreenivas, 2014b: Interdecadal modulation of ENSO teleconnections to the Indian Ocean in a coupled model: Special emphasis on decay phase of El Niño. Global Planet. Change, 112, 33-40, https://doi.org/ 10.1016/j.gloplacha.2013.11.003.

Day, J. A., I. Fung, and C. Risi, 2015: Coupling of South and East Asian monsoon precipitation in July-August. J. Climate, 28, 4330-4356, https://doi.org/10.1175/JCLI-D-14-00393.1.

Dee, D. P., and Coauthors, 2011: The ERA-Interim reanalysis: Configuration and performance of the data assimilation system. Quart. J. Roy. Meteor. Soc., 137, 553-597, https://doi.org/ 10.1002/qj.828.

Ding, Q., and B. Wang, 2005: Circumglobal teleconnection in the Northern Hemisphere summer. J. Climate, 18, 3483-3505, https://doi.org/10.1175/JCLI3473.1.

Ding, R., K. J. Ha, and J. Li, 2010: Interdecadal shift in the relationship between the East Asian summer monsoon and the tropical Indian Ocean. Climate Dyn., 34, 1059-1071, https:// doi.org/10.1007/s00382-009-0555-2.

Ding, Y., 2007: The variability of the Asian summer monsoon. J. Meteor. Soc. Japan, 85B, 21-54, https://doi.org/10.2151/ jmsj.85B.21.

- - and Y.-Y. Liu, 2008: A study of the teleconnections in the Asian-Pacific monsoon regions. Acta Meteor. Sin., 22, 404-417.

Enomoto, T., B. J. Hoskins, and Y. Matsuda, 2003: The formation mechanism of the Bonin high in August. Quart. J. Roy. Meteor. Soc., 129, 157-178, https://doi.org/10.1256/ qj.01.211.

Ha, K.-J., Y.-W. Seo, J.-Y. Lee, R. H. Kripalani, and K.-S. Yun, 2017: Linkages between the South and East Asian summer monsoons: A review and revisit. Climate Dyn., 51, 4207-4227, https://doi.org/10.1007/s00382-017-3773-z.

He, Z., and D. Gong, 2002: Interdecadal change in western Pacific subtropical high and climatic effects. J. Geogr. Sci., 12, 202 209, https://doi.org/10.1007/BF02837475.

Hirota, N., and M. Takahashi, 2012: A tripolar pattern as an internal mode of the East Asian summer monsoon. Climate Dyn., 39, 2219-2238, https://doi.org/10.1007/s00382-012-1416-y.

Hu, K., G. Huang, and R. Wu, 2013: A strengthened influence of ENSO on August high temperature extremes over the southern Yangtze River valley since the late 1980s. J. Climate, 26, 2205-2221, https://doi.org/10.1175/JCLI-D-12-00277.1.

Hu, Z.-Z., R. Wu, J. L. Kinter, and S. Yang, 2005: Connection of summer rainfall variations in South and East Asia: Role of E Niño-Southern Oscillation. Int. J. Climatol., 25, 1279-1289, https://doi.org/10.1002/joc.1159.

Huang, G., Y. Liu, and R. Huang, 2011: The interannual variability of summer rainfall in the arid and semiarid regions of northern China and its association with the Northern Hemisphere circumglobal teleconnection. Adv. Atmos. Sci., 28, 257-268, https://doi.org/10.1007/s00376-010-9225-x.

Huang, R., and W. Li, 1987: Influence of the heat source anomaly over the western tropical Pacific on the subtropical high over East Asia (in Chinese). Proc. Int. Conf. on the General Circulation of East Asia, Chengdu, China, Institute of Atmospheric
Physics and Lanzhou Institute of Plateau Atmospheric Physics, Chinese Academy of Sciences, 40-51.

—, L. Zhou, and W. Chen, 2003: The progresses of recent studies on the variabilities of the East Asian monsoon and their causes. Adv. Atmos. Sci., 20, 55-69, https://doi.org/10.1007/BF03342050.

_ - Y. Liu, and T. Feng, 2013: Interdecadal change of summer precipitation over eastern China around the late-1990s and associated circulation anomalies, internal dynamical causes. Chin. Sci. Bull., 58, 1339-1349, https://doi.org/10.1007/s11434012-5545-9.

, — - Z. Du, J. Chen, and J. Huangfu, 2017: Differences and links between the East Asian and South Asian summer monsoon systems: Characteristics and variability. Adv. Atmos. Sci., 34, 1204-1218, https://doi.org/10.1007/s00376-017-7008-3.

Kalnay, E., and Coauthors, 1996: The NCEP/NCAR 40-Year Reanalysis Project. Bull. Amer. Meteor. Soc., 77, 437-471, https:// doi.org/10.1175/1520-0477(1996)077<0437:TNYRP>2.0.CO;2.

Kamae, Y., M. Watanabe, M. Kimoto, and H. Shiogama, 2014: Summertime land-sea thermal contrast and atmospheric circulation over East Asia in a warming climate-Part I: Past changes and future projections. Climate Dyn., 43, 2553-2568, https://doi.org/10.1007/s00382-014-2073-0.

Kim, B.-J., S.-E. Moon, R.-Y. Lu, and R. H. Kripalani, 2002: Teleconnections: Summer monsoon over Korea and India. Adv. Atmos. Sci., 19, 665-676, https://doi.org/10.1007/s00376-002-0006-z.

Kobayashi, S., and Coauthors, 2015: The JRA-55 reanalysis: General specifications and basic characteristics. J. Meteor. Soc. Japan, 93, 5-48, https://doi.org/10.2151/jmsj.2015-001.

Kosaka, Y., H. Nakamura, M. Watanabe, and M. Kimoto, 2009: Analysis on the dynamics of a wave-like teleconnection pattern along the summertime Asian jet based on a reanalysis dataset and climate model simulations. J. Meteor. Soc. Japan, 87, 561-580, https://doi.org/10.2151/jmsj.87.561.

- S.-P. Xie, N.-C. Lau, and G. A. Vecchi, 2013: Origin of seasonal predictability for summer climate over the northwestern Pacific. Proc. Natl. Acad. Sci. USA, 110, 7574-7579, https:// doi.org/10.1073/pnas.1215582110.

Kripalani, R. H., and S. V. Singh, 1993: Large scale aspects of IndiaChina summer monsoon rainfall. Adv. Atmos. Sci., 10, 71-84, https://doi.org/10.1007/BF02656955.

, and A. Kulkarni, 1997: Rainfall variability over South-east Asia-Connections with Indian monsoon and ENSO extremes: New perspectives. Int. J. Climatol., 17, 1155-1168, https://doi.org/10.1002/(SICI)1097-0088(199709)17:11<1155:: AID-JOC188>3.0.CO;2-B.

$\longrightarrow$, and —, 2001: Monsoon rainfall variations and teleconnections over South and East Asia. Int. J. Climatol., 21, 603-616, https://doi.org/10.1002/joc.625.

— - - and S. V. Singh, 1997: Association of the Indian summer monsoon with the Northern Hemisphere mid-latitude circulation. Int. J. Climatol., 17, 1055-1067, https://doi.org/10.1002/(SICI)10970088(199708)17:10<1055::AID-JOC180>3.0.CO;2-3.

- J. H. Oh, and H. S. Chaudhari, 2010: Delayed influence of the Indian Ocean Dipole mode on the East Asia-West Pacific monsoon: Possible mechanism. Int. J. Climatol., 30, 197-209, https://doi.org/10.1002/joc.1890.

Lau, K. M., and H. T. Wu, 2001: Principal modes of rainfall-SST variability of the Asian summer monsoon-A reassessment of the monsoon-ENSO relationship. J. Climate, 14, 28802895, https://doi.org/10.1175/1520-0442(2001)014<2880: PMORSV $>2.0 . \mathrm{CO} ; 2$.

, K.-M. Kim, and S. Yang, 2000: Dynamical and boundary forcing characteristics of regional components of the Asian 
summer monsoon. J. Climate, 13, 2461-2482, https://doi.org/ 10.1175/1520-0442(2000)013<2461:DABFCO >2.0.CO;2.

Li, X., and W. Zhou, 2012: Quasi-4-yr coupling between El NiñoSouthern Oscillation and water vapor transport over East Asia-WNP. J. Climate, 25, 5879-5891, https://doi.org/10.1175/ JCLI-D-11-00433.1.

— Z Z. Wen, W. Zhou, and D. Wang, 2012: Atmospheric water vapor transport associated with two decadal rainfall shifts over East China. J. Meteor. Soc. Japan, 90, 587-602, https://doi.org/ 10.2151/jmsj.2012-501.

Liu, Y., and Y. Ding, 2008: Analysis and numerical simulation of the teleconnection between Indian summer monsoon and precipitation in North China. Acta Meteor. Sin., 66, 789-799.

Lu, R., J.-H. Oh, and B.-J. Kim, 2002: A teleconnection pattern in upper-level meridional wind over the North African and Eurasian continent in summer. Tellus, 54A, 44-55, https:// doi.org/10.3402/tellusa.v54i1.12122.

Metz, W., 1991: Optimal relationship of large-scale flow patterns and the barotropic feedback due to high-frequency eddies. $J$. Atmos. Sci., 48, 1141-1159, https://doi.org/10.1175/15200469(1991)048<1141:OROLSF $>2.0$.CO;2.

Nitta, T., 1987: Convective activities in the tropical western Pacific and their impact on the Northern Hemisphere summer circulation. J. Meteor. Soc. Japan, 65, 373-390, https://doi.org/ 10.2151/jmsj1965.65.3_373.

Park, J. Y., J. G. Jhun, S. Y. Yim, and W. M. Kim, 2010: Decadal changes in two types of the western North Pacific subtropical high in boreal summer associated with Asian summer monsoon/ El Niño-Southern Oscillation connections. J. Geophys. Res., 115, D21129, https://doi.org/10.1029/2009JD013642.

Poli, P., and Coauthors, 2016: ERA-20C: An atmospheric reanalysis of the twentieth century. J. Climate, 29, 4083-4097, https://doi.org/10.1175/JCLI-D-15-0556.1.

Rayner, N. A., D. E. Parker, E. B. Horton, C. K. Folland, L. V. Alexander, D. P. Rowell, E. C. Kent, and A. Kaplan, 2003: Global analyses of sea surface temperature, sea ice, and night marine air temperature since the late nineteenth century. J. Geophys. Res., 108, 4407, https://doi.org/10.1029/2002JD002670.

Seager, R., N. Naik, and G. A. Vecchi, 2010: Thermodynamic and dynamic mechanisms for large-scale changes in the hydrological cycle in response to global warming. J. Climate, 23, 4651-4668, https://doi.org/10.1175/2010JCLI3655.1.

Song, F., and T. Zhou, 2015: The crucial role of internal variability in modulating the decadal variation of the East Asian summer monsoon-ENSO relationship during the twentieth century. J. Climate, 28, 7093-7107, https://doi.org/10.1175/JCLI-D-1400783.1.

Takaya, K., and H. Nakamura, 2001: A formulation of a phaseindependent wave-activity flux for stationary and migratory quasigeostrophic eddies on a zonally varying basic flow. J. Atmos. Sci., 58, 608-627, https://doi.org/10.1175/15200469(2001)058<0608:AFOAPI >2.0.CO;2.

Tao, S.-Y., and L. Chen, 1987: A review of recent research on the East Asian summer monsoon in China. Monsoon Meteorology, C.-P. Chang and T.N. Krishnamurti, Eds., Oxford University Pres 60-92.

Uppala, S. M., and Coauthors, 2005: The ERA-40 Re-Analysis. Quart. J. Roy. Meteor. Soc., 131, 2961-3012, https://doi.org/ 10.1256/qj.04.176.

Wakabayashi, S., and R. Kawamura, 2004: Extraction of major teleconnection patterns possibly associated with the anomalous summer climate in Japan. J. Meteor. Soc. Japan, 82, 15771588, https://doi.org/10.2151/jmsj.82.1577.
Wang, B., R.-G. Wu, and K.-M. Lau, 2001: Interannual variability of the Asian summer monsoon: Contrasts between the Indian and the western North Pacific-East Asian monsoons. J. Climate, 14, 4073-4090, https://doi.org/10.1175/15200442(2001)014<4073:IVOTAS > 2.0.CO;2.

Wang, H., B. Wang, F. Huang, Q. Ding, and J.-Y. Lee, 2012: Interdecadal change of the boreal summer circumglobal teleconnection (1958-2010). Geophys. Res. Lett., 39, L12704, https://doi.org/10.1029/2012GL052371.

Wang, L., P. Xu, W. Chen, and Y. Liu, 2017: Interdecadal variations of the Silk Road pattern. J. Climate, 30, 9915-9932, https://doi.org/10.1175/JCLI-D-17-0340.1.

Wang, S., and J. Huang, 2006: Instability of precipitation teleconnection between North China and India. Prog. Nat. Sci., 16, 980-985.

Wu, R., 2002: A mid-latitude Asian circulation anomaly pattern in boreal summer and its connection with the Indian and East Asian summer monsoons. Int. J. Climatol., 22, 1879-1895, https://doi.org/10.1002/joc.845.

_ 2017: Relationship between Indian and East Asian summer rainfall variations. Adv. Atmos. Sci., 34, 4-15, https://doi.org/ 10.1007/s00376-016-6216-6.

— and B. Wang, 2002: A contrast of the East Asian summer monsoon-ENSO relationship between $1962-77$ and 1978 93. J. Climate, 15, 3266-3279, https://doi.org/10.1175/15200442(2002)015<3266:ACOTEA>2.0.CO;2.

Xie, S.-P., K. Hu, J. Hafner, H. Tokinaga, Y. Du, G. Huang, and T. Sampe, 2009: Indian Ocean capacitor effect on Indo-western Pacific climate during the summer following El Niño. J. Climate, 22, 730-747, https://doi.org/10.1175/2008JCLI2544.1.

—, Y. Du, G. Huang, X.-T. Zheng, H. Tokinaga, K. Hu, and Q. Liu, 2010: Decadal shift in El Niño influences on Indowestern Pacific and East Asian climate in the 1970s. J. Climate, 23, 3352-3368, https://doi.org/10.1175/2010JCLI3429.1.

_ , Y. Kosaka, Y. Du, K. Hu, J. S. Chowdary, and G. Huang, 2016: Indo-western Pacific Ocean capacitor and coherent climate anomalies in post-ENSO summer: A review. Adv. Atmos. Sci., 33, 411-432, https://doi.org/10.1007/s00376-015-5192-6.

Yun, K.-S., J.-Y. Lee, and K.-J. Ha, 2014: Recent intensification of the South and East Asian monsoon contrast associated with an increase in the zonal tropical SST gradient. J. Geophys. Res., 119, 8104-8116, https://doi.org/10.1002/2014JD021692.

Zhang, R., 2001: Relations of water vapor transport from Indian monsoon with that over East Asia and the summer rainfall in China. Adv. Atmos. Sci., 18, 1005-1017, https://doi.org/ 10.1007/BF03403519.

— A. Sumi, and M. Kimoto 1999: A diagnostic study of the impact of El Niño on the precipitation in China. Adv. Atmos. Sci., 16, 229-241, https://doi.org/10.1007/BF02973084.

_ Q. Min, and J. Su, 2017: Impact of El Niño on atmospheric circulations over East Asia and rainfall in China: Role of the anomalous western North Pacific anticyclone. Sci. China Earth Sci., 60, 1124-1132, https://doi.org/10.1007/s11430-016-9026-x.

Zheng, F., J. Li, Y. Li, S. Zhao, and D. Deng, 2016: Influence of the summer NAO on the spring-NAO-based predictability of the East Asian summer monsoon. J. Climate, 55, 1459-1476, https://doi.org/10.1175/JAMC-D-15-0199.1.

Zhou, T., and R. Yu, 2005: Atmospheric water vapor transport associated with typical anomalous summer rainfall patterns in China. J. Geophys. Res., 110, D08104, https://doi.org/10.1029/ 2004JD005413. 